\title{
An evapotranspiration product for arid regions based on the three-temperature model and thermal remote sensing
}

\author{
Yu Jiu Xiong a,b, Shao Hua Zhao ${ }^{c}$, Fei Tian ${ }^{\mathrm{d}}$, Guo Yu Qiu ${ }^{\mathrm{e}, *}$ \\ ${ }^{a}$ Department of Water Resource and Environments, School of Geography and Planning, Sun Yat-Sen University, Guangzhou, Guangdong, China \\ ${ }^{\mathrm{b}}$ Key Laboratory of Water Cycle and Water Security in Southern China of Guangdong High Education Institute, Sun Yat-Sen University, Guangzhou, Guangdong, China \\ ' Satellite Environment Center, Ministry of Environmental Protection, State Environmental Protection Key Laboratory of Satellite Remote Sensing, Beijing, China \\ ${ }^{\mathrm{d}}$ State Key Laboratory of Urban and Regional Ecology, Research Center for Eco-Environmental Sciences, Chinese Academy of Sciences, Beijing, China \\ ${ }^{\text {e }}$ Shenzhen Engineering Laboratory for Water Desalinization with Renewable Energy, School of Environment and Energy, Peking University, Shenzhen, Guangdong, China
}

\section{A R T I C L E I N F O}

\section{Article history:}

Received 9 July 2015

Received in revised form 13 September 2015

Accepted 21 September 2015

Available online 28 September 2015

This manuscript was handled by Peter K.

Kitanidis, Editor-in-Chief, with the

assistance of J.A. Huisman, Associate Editor

\section{Keywords:}

Evapotranspiration

Evaporation

Transpiration

MOD16

Heihe River Basin

Shiyanghe River Basin

\begin{abstract}
S U M M A R Y
An accurate estimation of evapotranspiration (ET) is crucial to better understand the water budget and improve related studies. Satellite remote sensing provides an unprecedented opportunity to map the spatiotemporal distribution of ET. However, ET values from barren or sparsely vegetated areas in arid regions are often assumed to be zero in typical ET products because of their low values. In addition, separating ET into soil evaporation $\left(E_{s}\right)$ and vegetation transpiration $\left(E_{c}\right)$ is difficult. To address these challenges, we developed an ET product (MOD3T) based on a three-temperature model and thermal remote sensing, specifically Moderate Resolution Imaging Spectroradiometer (MODIS) data. MOD3T has a spatial resolution of $1 \mathrm{~km}$ and a temporal resolution of 8 days. All input parameters except air temperature were obtained from MODIS datasets. Validation in two adjacent arid river basins in northwestern China showed that the mean absolute errors (mean absolute percent errors) between the MOD3T and flux tower ET were $0.71 \mathrm{~mm} \mathrm{~d}^{-1}(18.5 \%)$ and $0.16 \mathrm{~mm} \mathrm{~d}^{-1}$ (24.9\%) for a densely vegetated area and sparsely vegetated sandy desert, respectively. The error between the MOD3T and water balance ET was $24 \mathrm{~mm} \mathrm{y}^{-1}$ (8.1\%). The $E_{c} / \mathrm{ET}$ or $E_{s} / \mathrm{ET}$ of MOD3T was comparable to the observed stable oxygen and hydrogen isotopes. Unlike the MODIS ET (MOD16), MOD3T could not provide continuous ET values (as $70 \%$ of the MOD16 area lacked data) but exhibited relatively low uncertainty, particularly in cold seasons. Therefore, MOD3T can provide ET, $E_{s}$ and $E_{c}$ estimates for arid regions within acceptable ranges.
\end{abstract}

(c) 2015 Elsevier B.V. All rights reserved.

\section{Introduction}

Evapotranspiration (ET), which includes evaporation from soil and water surfaces and transpiration from vegetation, is a major hydrological variable that links water, energy and carbon cycles (Law et al., 2002; Kothavala et al., 2005; Anderson et al., 2008; Wang, 2008; Yang et al., 2014). Therefore, accurate ET estimates are required to understand local to global water and energy cycles and improve hydrological applications (Nemani et al., 2002; Dirmeyer et al., 2006; Trenberth et al., 2007; Cheng et al., 2011), water resource management (Bastiaanssen et al., 2005; Oki and Kanae, 2006; Yang et al., 2012), drought monitoring and assessment (Heim, 2002; Yao et al., 2011), irrigation scheduling (Allen et al., 1998; Dodds et al., 2005) and climatological studies (Pielke et al., 1998; Teuling et al., 2009). However, ET is one of the most

\footnotetext{
* Corresponding author. Tel./fax: +86 75526033309.

E-mail address: qiugy@pkusz.edu.cn (G.Y. Qiu).
}

problematic components of the water cycle to accurately quantify (Mu et al., 2007; Long et al., 2014) because of the heterogeneity of land surfaces and the large number of controlling factors that are involved, such as plant biophysics, soil properties, atmospheric conditions and topography (Shuttleworth and Wallace, 1985; Bastiaanssen et al., 1998; Glenn et al., 2007).

Numerous methods (e.g., weighing lysimetry, the Bowen ratio system and the eddy covariance technique) have been proposed to measure or estimate ET based on ground measurements; however, these methods are usually applicable to homogeneous areas that are smaller than $1 \mathrm{~km}^{2}$ (Scott et al., 2000; Baldocchi, 2003; Allen et al., 2011). Ground-based methodologies are inadequate for regional- and global-scale requirements (Wang and Dickinson, 2012). Because satellite remote sensing provides temporally and spatially continuous information over land surfaces that is useful for estimating surface biophysical variables, this approach has been increasingly used to map the spatial distribution of ET at regional (e.g., Moran et al., 1989; Norman et al., 
1995; Bastiaanssen et al., 1998; Li et al., 2005; Allen et al., 2007; Cleugh et al., 2007; Yang and Shang, 2013) to global scales (e.g., Mu et al., 2007, 2011; Jung et al., 2010; Zhang et al., 2010; Vinukollu et al., 2011).

Moderate Resolution Imaging Spectroradiometer (MODIS) ET (MOD16) (Mu et al., 2007, 2011) and global land ET (Jung et al., 2010; Zhang et al., 2009, 2010) have been produced at the global scale based on the Penman-Monteith equation. These ET products provide important information on global terrestrial water and energy cycles and environmental changes (e.g., Loarie et al., 2011; Mu et al., 2013; Schlesinger and Jasechko, 2014). Although substantial progress has been made in ET studies ( $\mathrm{Li}$ et al., 2009a; Allen et al., 2011; Wang et al., 2013), accurately estimating ET based on remote sensing is a challenge, particularly in arid regions with large barren or sparsely vegetated areas. For example, the ET in barren/desert regions is often excluded from model calculations and is set to zero in the two global ET products. The annual ET in arid regions could exceed $200 \mathrm{~mm}$ (Tian et al., 2013, 2014), and neglecting soil moisture restrictions on transpiration would cause an underestimation of the MOD16 and global land ET (Mu et al., 2011; Yang et al., 2015). Mu et al. (2007) suggested that further research is required to improve this algorithm in barren areas. Furthermore, barren/desert regions account for $24 \%$ of the Earth's land surface; the ET in these regions is important for regional and global water budgets (Falkenmark and Rockstrom, 2004; Bastiaanssen et al., 2005; Li et al., 2009a).

In addition, the Penman-Monteith equation and some methods that are based on the energy balance equation require surface and aerodynamic resistances to estimate water vapor transfer in the soil-vegetation-atmosphere system. However, these resistances are difficult to quantify (Priestley and Taylor, 1972; Qiu, 1996; Qiu et al., 1996, 1998), especially in arid regions that are characterized by aerodynamic and land surface properties with high spatial heterogeneity, because the resistances are significantly affected by aerodynamic and land surface properties. In fact, the parameterization of resistance is one of the greatest limitations when remotely estimating ET (Li et al., 2009a; Matsushita and Fukushima, 2009; Vinukollu et al., 2011). The improper parameterization of resistance might lead to error propagation. Our previous results showed that the observations were better fit by the ET that was estimated without aerodynamic resistance than the ET that was estimated with aerodynamic resistance (Xiong and Qiu, 2014). In addition, the available ET products, including the two mainstream ET datasets, are seldom partitioned into the two ET components of soil evaporation $\left(E_{s}\right)$ and vegetation transpiration $\left(E_{c}\right)$ (Schlesinger and Jasechko, 2014).

The objective of this study is to estimate and develop an ET product that includes both soil evaporation and vegetation transpiration for arid regions based on a three-temperature model (3T model) to address two limitations in ET estimation: the assumption that the ET values from barren or sparsely vegetated areas in arid regions are zero in typical ET products, and the difficulty in separating ET into soil evaporation $\left(E_{s}\right)$ and vegetation transpiration $\left(E_{c}\right)$.

\section{Development of an ET product for arid regions}

\subsection{Theoretical basis of the $3 T$ model}

The 3T model can be expressed as follows (Qiu, 1996):

$L E_{s}=R_{n, s}-G_{s}-\left(R_{n, s r}-G_{s r}\right) \frac{T_{s}-T_{a}}{T_{s r}-T_{a}} \quad$ soil

$L E_{c}=R_{n, c}-R_{n, c r} \frac{T_{c}-T_{a}}{T_{c r}-T_{a}} \quad$ vegetation
For a mixture of soil and vegetation,

$L(\mathrm{ET})=L E_{s}+L E_{c}$

where ET is the evapotranspiration; $E_{s}$ and $E_{c}$ are the soil and vegetation components of ET within a given pixel, respectively, in $\mathrm{mm}$; $L$ is the latent heat of vaporization; the subscripts "s," "c," " $a$," "sr" and " $c r$ " represent the soil, canopy, air, reference soil and reference canopy, respectively; $R_{n}$ is the net radiation in $\mathrm{W} \mathrm{m}^{-2} ; G$ is the soil heat flux in $\mathrm{W} \mathrm{m}^{-2}$; and $T$ is the temperature in $\mathrm{K}$.

Although the 3T model was based on the energy balance, a reference surface (a surface without evaporation or transpiration) was introduced to eliminate sensible heat flux and aerodynamic resistance (Qiu, 1996; Qiu et al., 1996, 1998). This variable constitutes the greatest difference between the 3T model and other ET estimation methods that include resistance deduced from the energy balance, such as the surface energy balance algorithm for land (SEBAL) (Bastiaanssen et al., 1998), surface energy balance system (SEBS) (Su, 2002; Jia et al., 2003), Penman-Monteith equation (Cleugh et al., 2007) and two-source energy balance model (TSEB) (Norman et al., 1995).

We previously proposed two parameterization methods for remote sensing applications of the 3T model: a 3T-R model (Xiong and Qiu, 2011) and a 3T-S model (Xiong and Qiu, 2014). The differences between the 3T-R and 3T-S models are a function of the method that is used to obtain the reference temperatures $\left(T_{s r}\right.$ and $T_{c r}$ ). In the 3T-R model, $T_{s r}$ and $T_{c r}$ are obtained by inverting the energy balance method, which leads to an aerodynamic resistance requirement:

$T_{s r}=\frac{R_{n, s}-G_{s}}{\rho C_{p}} r_{a}+T_{a}$

$T_{c r}=\frac{R_{n, c}}{\rho C_{p}} r_{a}+T_{a}$

where $T_{s r}$ and $T_{c r}$ represent the reference soil temperature and reference canopy temperature, respectively; $r_{a}$ is the aerodynamic resistance (the diffusion resistance of the air layer to water vapor movement) in $\mathrm{s} \mathrm{m}^{-1} ; \rho$ is the air density in $\mathrm{kg} \mathrm{m}^{-3}$; and $C_{p}$ is the specific heat of air at a constant pressure in $\mathrm{MJ} \mathrm{kg}^{-1}{ }^{\circ} \mathrm{C}^{-1}$. The remaining parameters are the same as those in Eqs. (1) and (2).

In the 3T-S model, $T_{s r}$ and $T_{c r}$ are assumed to be the regional maximum values for soil surface temperature and vegetation temperature, respectively, which are collected from a region with approximately equivalent solar radiation and terrain:

$T_{s r}=T_{s, \max }=\max \left(T_{s 1}, T_{s 2}, \ldots, T_{s i}\right)$

$T_{c r}=T_{c, \max }=\max \left(T_{c 1}, T_{c 2}, \ldots, T_{c i}\right)$

where $T_{s i}$ and $T_{c i}$ represent the soil and vegetation components of land surface temperature (LST) within pixel $i(i=1,2,3, \ldots)$, respectively. For commonly used LSTs that are estimated from singleview-angle satellite data, $T_{S}$ and $T_{c}$ can only be decomposed through certain assumptions; for example, this study assumes that LST is a vegetation-weighted summation of $T_{S}$ and $T_{c}$ (see Section 2.2 for details).

Thus, the simplification of obtaining the reference temperatures ( $T_{s r}$ and $T_{c r}$ ) with only remotely sensed land surface temperature makes the 3T-S model more viable. Although observations from only two Bowen flux towers over several days were used, our previous validation results indicated that the $3 \mathrm{~T}-\mathrm{R}$ and $3 \mathrm{~T}-\mathrm{S}$ models can capture ET at $30 \mathrm{~m}$ resolution in semiarid grasslands in northern China (Xiong and Qiu, 2011, 2014). 


\subsection{Parameterization of model inputs}

Because our ET product is based on the 3T model and thermal remote sensing (mainly MODIS data), we named the product MOD3T. The MOD3T has spatial and temporal resolutions of $1 \mathrm{~km}$ and 8 days, respectively. The development of MOD3T is summarized in Fig. 1.

In addition to air temperature, which is commonly interpolated by using meteorological data, other input variables in the 3T model can be retrieved directly or indirectly from remote sensing data. Surface conditions, such as soil, vegetation and a combination thereof, can be determined by using the normalized difference vegetation index (NDVI), which can be obtained from the MOD13A2 product. When a pixel's NDVI is less than $N D V I_{\text {min }}$, the pixel is assumed to be a soil pixel. Pixels with an NDVI greater than $N D V I_{\max }$ are assumed to be vegetated pixels. When the NDVI is between $N D V I_{\min }$ and $N D V I_{\max }$, a pixel is considered to be a combination of soil and vegetation. NDVI thresholds $\left(N D V I_{\text {min }}\right.$ and $N D V I_{\max }$ ) can be determined from the lower and upper $3 \%$ tails of the NDVI distribution, excluding negative values. In this study, $N D V I_{\min }=0.2$ and $N D V I_{\max }=0.5$, as proposed by Sobrino et al. (2001).

\subsubsection{Net radiation}

$R_{n, c}$ and $R_{n, s}$, the total net radiation that is partitioned into the canopy and soil components, respectively, are estimated by using the leaf area index (LAI) (Kustas and Norman, 1999), which can be obtained from the MOD15A2 product. In barren or sparsely vegetated areas where MOD15A2 cannot provide an LAI value, these regions are assumed to have only soil evaporation, with no vegetation transpiration. Thus, $R_{n, c}=0$ and $R_{n, s}=R_{n}$.

$$
\begin{aligned}
R_{n, c} & =R_{n}[1-\exp (-0.45 L A I)] \\
R_{n, s} & =R_{n} \exp (-0.45 L A I) \\
R_{n}= & R_{s w d}-R_{s w u}+R_{l w d}-R_{l w u} \\
& =(1-\alpha) R_{s w d}+\varepsilon_{0} \varepsilon_{a} \sigma T_{a}^{4}-\varepsilon_{0} \sigma T_{s}^{4}
\end{aligned}
$$

where $R_{s w d}, R_{s w u}, R_{l w d}$ and $R_{l w u}$ represent the incoming short-wave radiation, outgoing short-wave radiation, incoming long-wave radiation and outgoing long-wave radiation, respectively; $\alpha$ is the land surface albedo, which is assumed to be the 20th band of the whitesky-albedo from the 8-day MCD43B3 product (Mu et al., 2011); $\sigma$ is the Stefan-Boltzmann constant $\left(5.67 \times 10^{-8} \mathrm{~W} \mathrm{~m}^{-2} \mathrm{~K}^{-4}\right)$; the land surface emissivity $\left(\varepsilon_{0}\right)$ can be calculated according to Sobrino et al. (2004); and the land atmospheric emissivity $\left(\varepsilon_{a}\right)$ can be estimated from the air temperature (Swinbank, 1963). A detailed description of the parameterization of net radiation can be found in Xiong and Qiu (2014).

\subsubsection{Soil heat flux}

If a pixel has $100 \%$ vegetation coverage, then the soil heat flux of that pixel is assumed to be zero. Otherwise, the soil heat flux $(G)$ can be directly extracted from the total net radiation by using Eq. (10) (Su, 2002).

$$
G=R_{n}\left[\Gamma_{c}+(1-f)\left(\Gamma_{s}-\Gamma_{c}\right)\right]
$$

where $f$ is the fractional vegetation cover and is assumed to be the 8-day MOD15A2 fraction of absorbed photosynthetically active

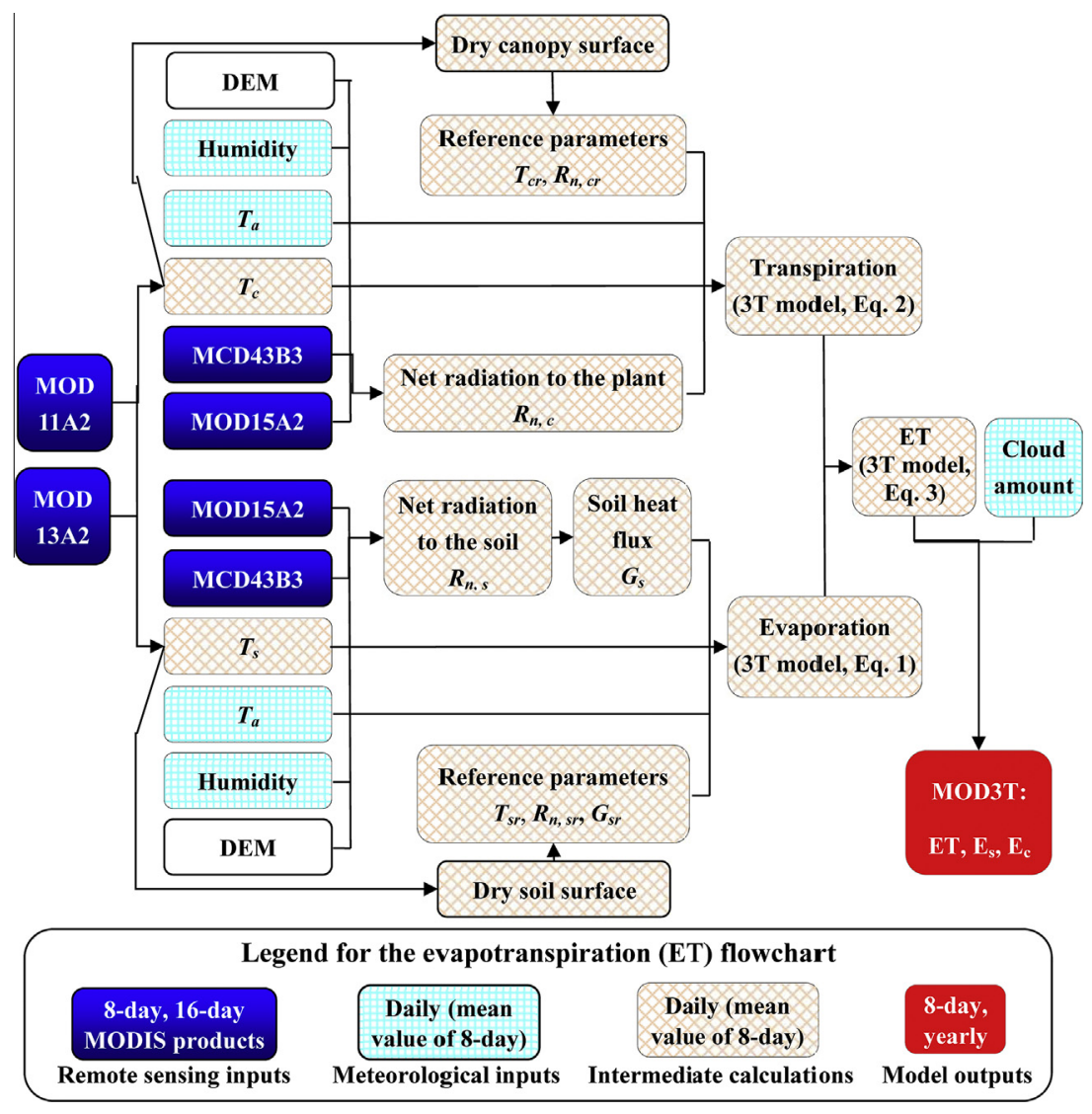

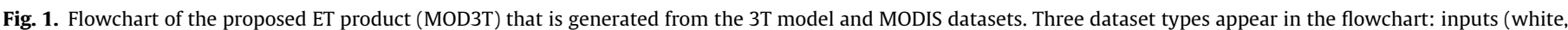

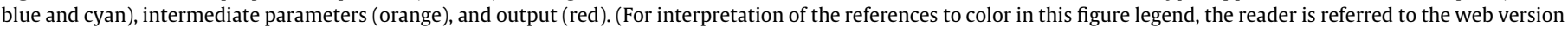
of this article.) 
radiation (FPAR) according to Los et al. (2000) and Mu et al. (2011). However, when the MOD15A2 FPAR is invalid, $f$ is estimated by using the NDVI, as suggested by Carlson et al. (1995). $\Gamma_{s}$ and $\Gamma_{c}$ are empirical coefficients, where $\Gamma_{s}=0.315$ (Kustas and Daughtry, 1990) and $\Gamma_{c}=0.05$ (Monteith, 1973).

\subsubsection{Soil and canopy temperatures}

$T_{s}$ and $T_{c}$ are the temperatures of the soil and vegetation components, respectively, within a given pixel and are estimated by using the temperature of a mixed pixel $\left(T_{m i x}\right)$ (Eq. (11)) (Lhomme et al., 1994):

$f T_{c}+(1-f) T_{s}=T_{\text {mix }}$

$T_{s}-T_{c}=a\left(T_{m i x}-T_{a}\right)^{m}$

where $a$ and $m$ are empirical coefficients with values $a=0.1$ and $m=2$, respectively. $T_{m i x}$ is assumed to be the 8 -day MODIS land surface temperature (LST) product (MOD11A2).

\subsubsection{Reference parameters}

The reference temperature is similar to the "hot pixel" in the SEBAL model. However, the hot pixel is retrieved from the vegetation index and LST relationship space (e.g., Long and Singh, 2013), whereas the reference temperatures $T_{s r}$ and $T_{c r}$ for each 8-day period are obtained by using Eqs. (6) and (7), respectively, based on decomposing the MODIS LST product, which has a size of approximately (3-4) $\times 10^{8}$ times the sensor pixel size over the study area (see Section 5.4 for details). To avoid outliers, the maximum value is averaged from the upper $1 \%$. The reference net radiation $\left(R_{n, s r}\right.$ or $\left.R_{n, c r}\right)$ and reference soil heat flux $\left(G_{s r}\right)$ are estimated by using Eqs. (12) and (13), respectively:

$$
\begin{aligned}
& R_{n, r}=f\left(R_{s w d}, \alpha_{r}, \varepsilon_{0 r}, T_{r}, T_{a}\right) \\
& =\left(1-\alpha_{r}\right) R_{s w d}+\varepsilon_{0 r} \varepsilon_{a} \sigma T_{a}^{4}-\varepsilon_{0 r} \sigma T_{r}^{4} \\
& G_{s r}=f\left(R_{n, s r}\right)=0.315 R_{n, s r}
\end{aligned}
$$

where the subscript " $r$ " refers to the reference site, i.e., the dry soil or dry canopy. The values $\alpha_{r}=0.275, \varepsilon_{0 r}=0.970$ and $T_{r}=T_{s r}$ are used for the dry soil, whereas the values $\alpha_{r}=0.225, \varepsilon_{0 r}=0.990$ and $T_{r}=T_{c r}$ are used for the dry canopy.

\subsection{Scaling remotely sensed instantaneous ET to daily or longer values}

The remotely sensed instantaneous ET can be scaled to a daily value by using Eq. (14) (Jackson et al., 1983), which is similar to the sinusoidal variation in solar radiation during the daytime on cloudless days. The daily ET can be summed to an 8-day value by using Eq. (15) and considering cloud effects:

$E T_{D}=E T_{i} \frac{2 N}{\pi \sin (\pi \cdot t / N)}$

$E T_{8-\text { day }}=a_{C}\left(8 E T_{D}\right)$
$a_{C}=\frac{D_{\text {clear }}+\left(8-D_{\text {clear }}\right)(1-C)}{8}$

where $\mathrm{ET}_{i}, \mathrm{ET}_{D}$ and $\mathrm{ET}_{8 \text {-day }}$ are the instantaneous, daily and 8-day ET rates, respectively. $N$ is the duration of evapotranspiration during the daytime and is assumed to be the daily sunshine hours minus $2 ; t$ is the time between sunrise and the data collection time of the passing satellite sensor; $a_{C}$ is a cloud coefficient; $D_{\text {clear }}$ is the greatest number of sunny days in each 8-day period; and $C$ is the mean total cloud cover during each 8 -day period. $D_{\text {clear }}$ and $C$ are interpolated by using observed values from meteorological stations.

\section{Materials and validation method}

A case study was conducted in two adjacent inland river basins, i.e., the Heihe River and Shiyanghe River Basins, in the arid region of northwestern China (Fig. 2).

\subsection{Study area}

The Heihe River Basin, which has an area of approximately $143600 \mathrm{~km}^{2}$, is located at $97^{\circ} 24^{\prime}-102^{\circ} 10^{\prime} \mathrm{E}$ and $37^{\circ} 41^{\prime}-42^{\circ} 42^{\prime} \mathrm{N}$ on the northern slopes of the Qilian Mountains. The Heihe River Basin is the second largest inland river basin (endorheic basin) in arid northern China. The main stream of the Heihe River, which has a length of $821 \mathrm{~km}$, originates in the Qilian Mountains, flows through the Hexi Corridor of Gansu Province and ends in two terminal lakes in the desert in the western Inner Mongolia Plateau (Fig. 2). The study area can be divided into upper, middle and lower reaches by two gauging stations that are located in the Heihe River (Fig. 2): Yingluoxia, which has a control area of $10009 \mathrm{~km}^{2}$ and is the boundary between the upper and middle reaches, and Zhengyixia, which has a control area of $35600 \mathrm{~km}^{2}$ and is the boundary between the middle and lower reaches. The water source area is the Qilian Mountains highland area in the south, where the elevation varies from 2000 to $5500 \mathrm{~m}$. The climate is cold and semi-arid with a mean annual precipitation of $200-600 \mathrm{~mm}$. The middle Hexi Corridor, which has an elevation of $1000-2000 \mathrm{~m}$ and an annual precipitation and pan evaporation of $100-250 \mathrm{~mm}$ and $1200-2200 \mathrm{~mm}$, respectively, is the most productive region and is characterized as cool and arid. The lower reach is the Alxa High Plain, which has a mean elevation of approximately $1000 \mathrm{~m}$ and a mean annual precipitation of less than $50 \mathrm{~mm}$. The terrain is mainly barren Gobi. In general, the climate of the watershed is characterized as arid with low precipitation and high evapotranspiration.

The Shiyanghe River Basin is approximately $41000 \mathrm{~km}^{2}$ and is located at $101^{\circ} 41^{\prime}-104^{\circ} 16^{\prime} \mathrm{E}$ and $36^{\circ} 29^{\prime}-39^{\circ} 27^{\prime} \mathrm{N}$ on the northern slopes of the Qilian Mountains. The Shiyanghe River originates in the Qilian Mountains and ends at the Minqin Oasis (Fig. 2). The climate of the watershed is similar to that of the Heihe River Basin.

In recent decades, population increases and rapid socioeconomic development have led to the exploitation of water and land resources in the upper and middle parts of the basins. As a consequence, a severe loss of natural vegetation, gradual soil salinization, desertification and a sharp decrease in water resources in the lower reaches have occurred (Chen et al., 2005; Qi and Luo, 2005; Wang et al., 2007).

\subsection{Validation of the ET product with flux tower data}

Flux tower ET values from two contrasting types of land (a sparsely vegetated area and a densely vegetated area) were used. We installed a Bowen flux tower in the sparsely vegetated sandy desert around the Minqin Oasis in the lower reach of the Shiyanghe River Basin to conduct observations between May 2010 and December 2011. The Bowen ratio system measured routine meteorological data (e.g., net radiation, air temperature and humidity) and soil heat flux. All data were collected by a data logger (model DT500 series 3, Datataker, Australia) every $5 \mathrm{~s}$, and the $10 \mathrm{~min}$ averages were calculated and stored. The daily ET (from sunrise to sunset) was calculated by summing the instantaneous values (the mean value for each $10 \mathrm{~min}$ interval) by using the Bowen ratio energy balance method (Bowen, 1926). A detailed description of the experiment and the ET calculation can be found in our previous publication (Qiu et al., 2015). Because the Bowen flux tower obtained data for approximately two years, the daily ET values in 


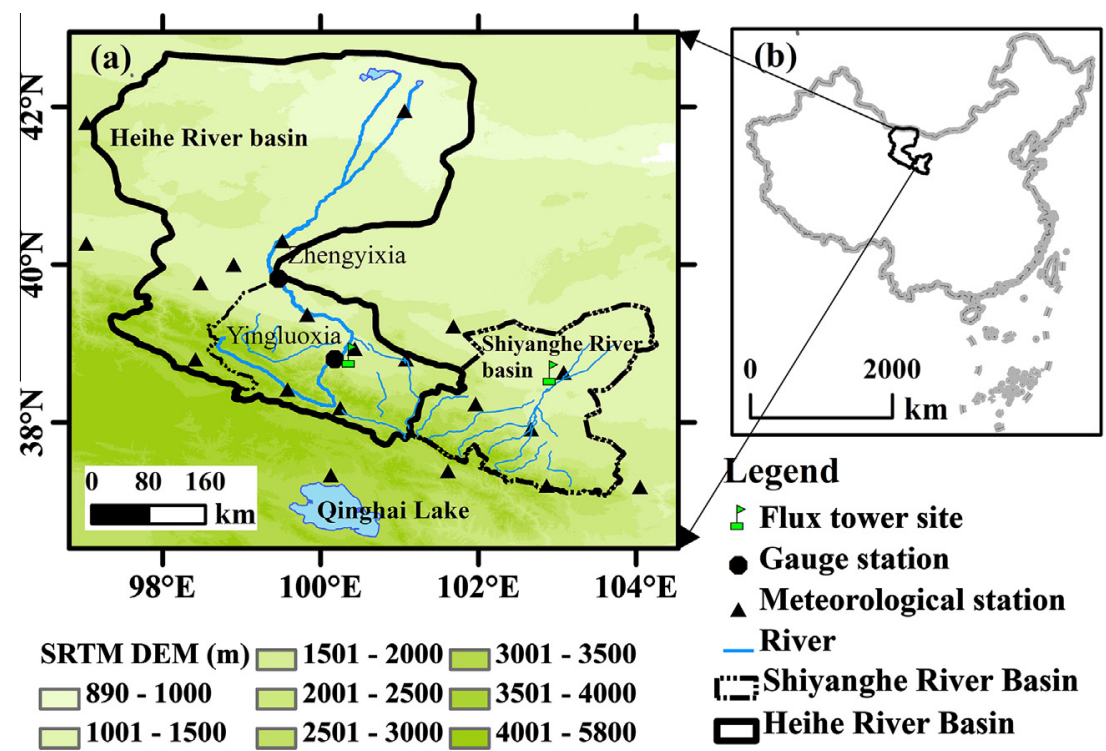

Fig. 2. Geographic information for the study area: (a) location and SRTM DEM of the two adjacent watersheds and (b) map of the selected study area in China.

each 8-day period according to the composition dates of the MODIS inputs (e.g., MOD11A2) were averaged to validate the proposed ET product.

At the densely vegetated site, which is a cropland (maize) area in the Daman Oasis of the middle Heihe River Basin, the eddy covariance flux tower ET was observed between June and September 2012 as part of the Heihe Watershed Allied Telemetry Experimental Research (HiWATER) project (see Li et al., 2009b, 2013 for details). The maize, which has a stand density of approximately 37 plants $\mathrm{m}^{2}$, is generally sown in late April and harvested over 10 days in the middle of September (Zhu et al., 2014). The eddy flux tower observations, which were sampled at a frequency of $10 \mathrm{~Hz}$ and recorded every $30 \mathrm{~min}$ on average, were processed and provided by Liu's group (Liu et al., 2011; Xu et al., 2013). To obtain daily values, we summed the 30 -min data from sunrise to sunset (approximately 6:30 to 19:30). Because the eddy flux tower observations are relatively short (three months), validation was performed at the daily scale, and the proposed ET product was generated by using the daily MODIS inputs (e.g., MOD11A1) and synchronous air temperatures from the eddy flux tower observations.

The mean absolute error (MAE) (Eq. (16)) and mean absolute percent error (MAPE) (Eq. (17)) were used to assess the performance of the developed product.

$$
\begin{aligned}
\mathrm{MAE} & =\frac{1}{n} \sum_{i=1}^{n}\left|M_{i}-O_{i}\right| \\
\mathrm{MPE} & =\frac{100}{\langle O\rangle}\left(\frac{1}{n} \sum_{i=1}^{n}\left|M_{i}-O_{i}\right|\right)
\end{aligned}
$$

where $M_{i}$ and $O_{i}$ are the paired model estimation and observation, respectively; $n$ is the number of data points; and $\langle 0\rangle$ is the mean value of the observations.

\subsection{Validation of the ET product with the water balance ET}

The modeled yearly ET was compared with the water balance ET $\left(\mathrm{ET}_{W B E}\right)$ from 2008 to 2011 (Table 1). Generally, the water balance for a river basin is expressed as Eq. (18) (Shi et al., 2007):

$E T_{W B E}=P-R-\Delta S$
Table 1

Calculation of the water balance $\mathrm{ET}\left(\mathrm{ET}_{\text {WBE }}\right)$.

\begin{tabular}{lllllll}
\hline \multirow{2}{*}{$\begin{array}{l}\text { Water balance } \\
\text { equation }\end{array}$} & Basin & Year & \multicolumn{3}{l}{ Observation } \\
\cline { 3 - 7 } & & & $P$ & $I$ & $R$ & $\mathrm{ET}_{\text {WBE }}$ \\
\hline ET $_{\text {WBE }}=P+I$ & Shiyanghe River Basin & 2008 & 229 & 59.6 & - & 288.6 \\
Eq. (19) & & 2009 & 221 & 56.4 & - & 277.4 \\
& & 2010 & 215 & 54.1 & - & 269.1 \\
& 2011 & 261 & 53.8 & - & 314.8 \\
& Heihe River Basin & 2008 & 266 & 18.8 & - & 284.8 \\
& & 2009 & 288 & 18.5 & - & 306.5 \\
& & 2010 & 273 & 18.5 & - & 291.5 \\
& & 2011 & 248 & 18.1 & - & 266.1 \\
ET $_{\text {WBE }}=P+I-R$ & Middle-upper & 2008 & 299 & 62.6 & 32 & 329.6 \\
Eq. (20) & reaches of the Heihe & & & & & \\
& River Basin & & & & & \\
& & 2009 & 287 & 62.9 & 33 & 316.9 \\
& & 2010 & 273 & 63.1 & 27 & 309.1 \\
& & 2011 & 256 & 61.4 & 31 & 286.4 \\
\hline
\end{tabular}

Note: $P$ (precipitation), $I$ (irrigation), $R$ (runoff) and $\mathrm{ET}_{W B E}$ (evapotranspiration) are in $\mathrm{mm}$. $P$ was calculated as the arithmetic mean of the meteorological stations within the basin. I and $R$ were originally in $\mathrm{m}^{3}$ and were converted to water depth $(\mathrm{mm})$ by dividing by the basin's size. The amount of irrigation water that was consumed in the middle-upper Heihe River Basin was assumed to be equal to the irrigation water that was consumed in Zhangye because this city covers nearly the entire middle basin and has the most productive agriculture. Similarly, the amount of irrigation water that was consumed within the Heihe River Basin was assumed to be equal to that consumed in Gansu Province because only sparse cropland exists within the lower basin in Inner Mongolia; the remaining land is mainly barren with sparse vegetation. All the irrigation data were provided by the Water Resources Bulletin of Gansu Province. $R$ is the runoff that was measured at the Zhengyixia gauge station and was provided by the River and Sediment Bulletin of China.

where $P, R, \mathrm{ET}_{W B E}$, and $\Delta S$ represent precipitation, runoff, ET, and water storage change, respectively.

Some research shows that $\Delta S$ may not be negligible in the Qilian Mountains at the annual scale, considering that it varies from 51 to $242 \mathrm{~mm}$ per year (Xu et al., 2014) and equals $19.7 \mathrm{~mm}$ over an 8-year period (Qin et al., 2013). However, $\Delta S$ may be negligible (close to zero) at the entire basin and middle-upper basin scales (Zhong et al., 2008; Qin et al., 2013). Because no $\Delta S$ values are available from the upper mountain basin, a comparison was performed for the middle-upper basin and the entire basin. As an endorheic basin, the horizontal fluxes of surface water and groundwater are retained in the terminal lakes in the desert to the north, 
and the water balance equation for the entire basin can be simplified as follows (Eq. (19)):

$E T_{W B E}=P+I$

In the middle basin, irrigation consumes the most water and was therefore added to the water balance. The water balance for the middle-upper Heihe River Basin is expressed by Eq. (20):

$E T_{W B E}=P+I-R$

\subsection{Data preparation}

The datasets in this study include hydrological, meteorological, remote sensing and geospatial data. The annual runoff data between 2008 and 2011 from the Zhengyixia gauging station were obtained from the Ministry of Water Resources of China. The meteorological data include daily observational values of air temperature, precipitation and relative humidity, which were recorded at 21 national meteorological stations (triangles in Fig. 2). The greatest number of sunny days $\left(D_{\text {clear }}\right)$ and the mean total cloud cover $(C)$ were obtained from the mean annual values at the same meteorological stations between 1981 and 2010.

The remote sensing data for the model input that were recorded between 2008 and 2011 include four MODIS products (version 5) from three adjacent tiles (h25v04, h25v05, and h26v05). These products include 8-day MODIS land surface temperature/emissivity data (MOD11A2), LAI and FPAR (MOD15A2) data, 16-day global MODIS vegetation indices (MOD13A2) and albedos (MCD43B3). The daily MODIS products (MOD11A1, MOD15A3 and MOD09GA) and synchronous air temperature from flux towers for the 2012 growing season are used. In addition, the MODIS land surface evapotranspiration product (MOD16) is used for comparison. All the MODIS datasets are freely available from the National Aeronautics and Space Administration (NASA) at http://e4ftl01.cr.usgs.gov/.

The geospatial data include a digital elevation model (DEM) and vector data for the administrative boundaries. The Shuttle Radar Topography Mission (SRTM) 90 m DEM (Jarvis et al., 2008) is used (http://srtm.csi.cgiar.org/) to parameterize the incoming shortwave radiation (see Xiong and Qiu (2014) for details).

The data processing steps are as follows. (1) Sets of three identical adjacent MODIS products that were obtained on the same day from two vertical tiles are mosaicked and projected to a spatial resolution of $1 \mathrm{~km}$ by using a universal transverse mercator (UTM) projection (WGS84, UTM zone 48N) with the MODIS Reprojection Tool and MODIS Conversion Toolkit. (2) All the meteorological data are averaged for every 8-day period according to the composition dates of the MODIS product each year and are then interpolated to a $1 \mathrm{~km}$ resolution by applying the inverse distance weight (IDW) interpolation method. (3) The DEM is preprocessed and projected onto the coordinate system with the same spatial resolution as the processed MODIS product.

\section{Validation results}

The ET product (MOD3T) was averaged over $3 \times 3$ pixel blocks around the center of the flux tower. A comparison and statistical analysis of the observations and estimations are shown in Figs. 3 and 4. The MAE and MAPE were $0.16 \mathrm{~mm} \mathrm{~d}^{-1}$ and $24.87 \%$, respectively, for the sparsely vegetated sandy desert in the Shiyanghe River Basin (Fig. 3) and $0.71 \mathrm{~mm} \mathrm{~d}^{-1}$ and $18.53 \%$, respectively, for the densely vegetated site in the Daman Oasis in the middle Heihe River Basin (Fig. 4). The differences in the MOD3T and flux ET may be caused by biases in the ET estimation (see Section 5.4 for details) and by uncertainties in the flux measurements. For example, the uncertainty (mean percent error) in the latent

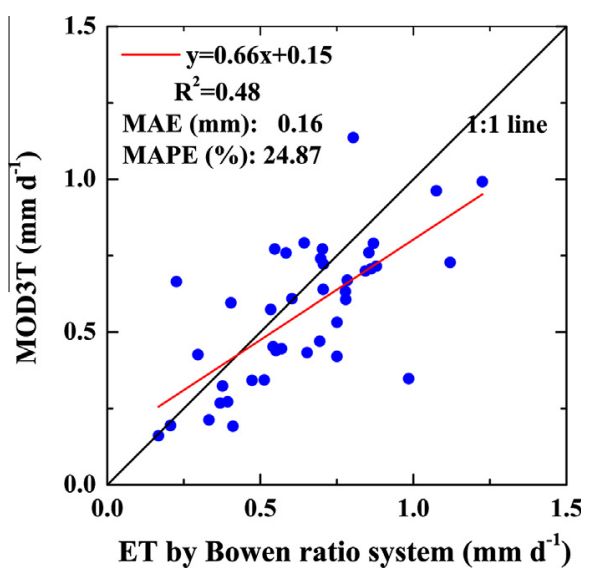

Fig. 3. Comparison of the daily ET values from the MOD3T and Bowen ratio flux tower at a sparsely vegetated sandy desert near the Minqin Oasis in the lower reach of the Shiyanghe River Basin. MAE and MAPE represent the mean absolute error and mean absolute percent error, respectively.

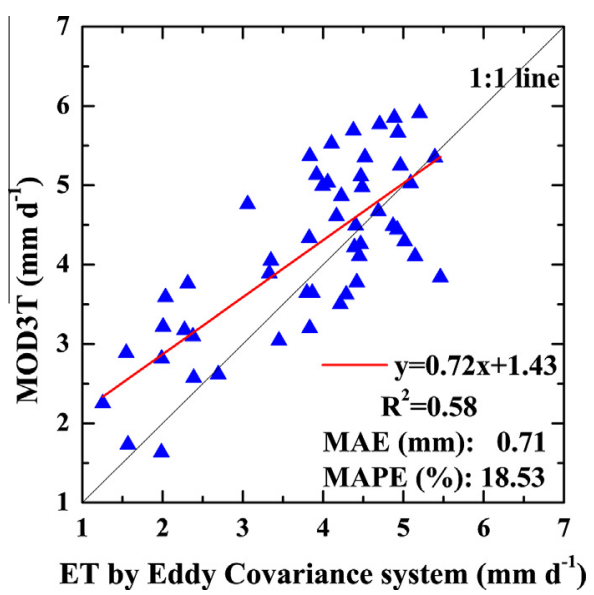

Fig. 4. Comparison of the daily ET values from MOD3T and eddy flux tower at a maize field within the Daman Oasis of the Heihe River Basin. Observations were recorded during the 2012 growing season. MAE and MAPE represent the mean absolute error and absolute percent error, respectively.

heat flux that was observed from the eddy correlation system of HiWATER is $9.3 \%$ for a desert steppe when using high-quality data (Xu et al., 2013). In addition, the bias in the ET estimations in the barren/desert area is larger than that in the vegetated area. Simulating the ET in the barren/desert area is likely to be difficult. One study showed that the latent heat flux estimation through a data assimilation scheme has a mean bias of $20.6-43.3 \mathrm{~W} \mathrm{~m}^{-2}$ and an RMSE of $64.5-80.2 \mathrm{~W} \mathrm{~m}^{-2}$ in a desert steppe in the middle Heihe River Basin (Xu et al., 2015). According to FAO paper 56 (Allen et al., 1998), $20.6 \mathrm{~W} \mathrm{~m}^{-2}$ is approximately equivalent to $0.73 \mathrm{~mm} \mathrm{~d}^{-1}$. Although MAPE was not provided in $\mathrm{Xu}$ et al. (2015), the minimum MAPE would be $20.6 \%$ based on their data. These results indicate that although errors exist in the MOD3T, the MAPE between the proposed ET product and observation is less than 25\%, indicating that the $3 \mathrm{~T}$ model is feasible for estimating ET in arid regions.

In contrast to the water balance ET, MOD3T was averaged based on the yearly ET values and boundaries of the basins; the results are shown in Fig. 5. A comparison between MOD3T and $\mathrm{ET}_{W B E}$ showed that (1) the MAE (MAPE) in the Shiyanghe River Basin was $20 \mathrm{~mm} \mathrm{y}^{-1}$ (6.93\%) over the four years; (2) the MAE (MAPE) over the entire Heihe River Basin was $23 \mathrm{~mm} \mathrm{y}^{-1}$ (8.04\%) over the four years, whereas the MAE (MAPE) between the MOD3T 


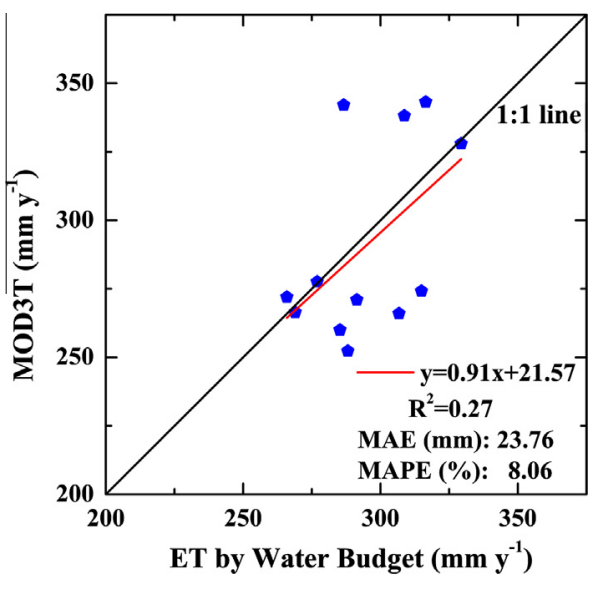

Fig. 5. Comparison of the annual ET values from MOD3T and the water budget in two adjacent inland river basins. MAE and MAPE represent the mean absolute error and mean absolute percent error, respectively.

and water balance ET was $28 \mathrm{~mm} \mathrm{y}^{-1}$ (9.11\%) in the middle-upper Heihe River Basin. Some studies (Long et al., 2014; Wang et al., 2014a, 2014b) showed that a water budget imbalance may lead to bias (varying from near zero to $\pm 30 \%$ of the precipitation) in the water balance ET, particularly when the regional precipitation exhibits large uncertainty because of sparse observations or inaccurate monitoring. Only ten meteorological stations are located within the Heihe River Basin; this data sparseness can cause uncertainty in the precipitation estimations. Kang et al. (2005) reported that the water budget imbalance was 3.90\% for the upper Heihe River Basin at a yearly scale by using Eq. (18). Assuming that the precipitation estimation has an uncertainty of $10 \%$ at the Heihe River Basin, the MAPE between the MOD3T and water balance ET would increase from $8.85 \%$ to $16.73 \%$ in 2008 . These results indicate that the proposed ET product is similar to the water balance ET at the yearly scale.

\section{Discussion}

\subsection{Comparison of MOD3T and MOD16}

As shown in Fig. 6, the MOD16 ET value only covers approximately $30 \%$ of the study area. The remaining $70 \%$ was classified as barren and sparsely vegetated with invalid values; by contrast, the proposed ET product has valid values for nearly the entire basin (Fig. 6). In areas where MOD16 has data, the annual ET distributions of the two estimations are similar. In other words, high ET values are often present in areas with abundant vegetation coverage, and low ET values occur in sparsely vegetated areas. The results indicate that both MOD3T and MOD16 produce a decreasing trend for ET from south to north. However, the proposed MOD3T can provide ET values for barren/desert areas.

The comparison revealed that MOD3T is more similar to the water balance ET than to MOD16 (Fig. 7) because MOD16 may be significantly biased (Vinukollu et al., 2011; Long et al., 2014). Fig. 8 may explain the source of these errors. The inter-annual changes in MOD16 fluctuated sharply. At the beginning and end of the year (e.g., the first three months), when the temperature is low, the MOD16 value at the basin scale is $0.82 \mathrm{~mm} \mathrm{~d}^{-1}$ on average, which may be impossible for cold regions. In the late growing season (DOY 265), the MOD16 value reaches $1.65 \mathrm{~mm} \mathrm{~d}^{-1}$ (the second peak in Fig. 8), which may also be incorrect. Feng et al. (2012) also reported that MOD16 can overestimate and underestimate ET in China's Loess Plateau. In fact, MOD16 has been shown to exhibit great uncertainty in relatively dry environments or conditions because of the inconsistency of the spatial resolution of the climate data and MODIS images and a lack of description for the soil moisture effect on soil evaporation, which leads to dampened spatial heterogeneity in MOD16 and an unreasonable spatial variability (Yang et al., 2013a, 2013b, 2015). Although soil moisture is not considered in the 3T model, the temperature difference ratio (e.g., $\left.\left(T_{s}-T_{a}\right) /\left(T_{s r}-T_{a}\right)\right)$ is used as an indicator of soil moisture.

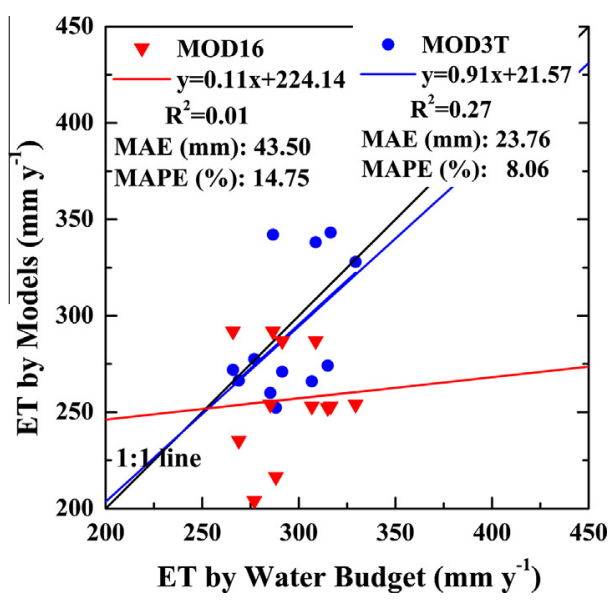

Fig. 7. ET that is estimated by the two models (MOD16 and MOD3T) compared to the water balance ET. MAE and MAPE represent the mean absolute error and mean absolute percent error, respectively.
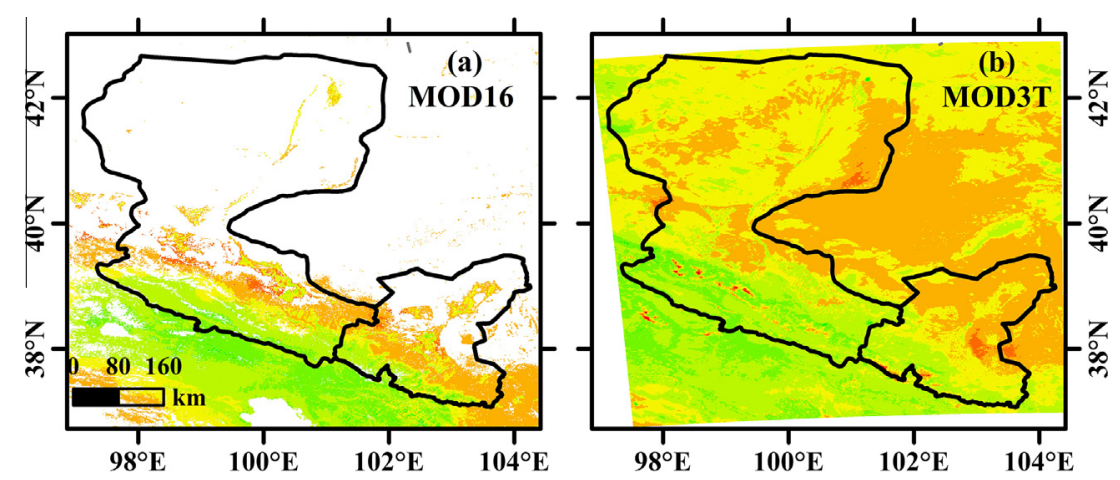

$\mathrm{ET}\left(\mathrm{mm} \mathrm{y} \mathrm{y}^{-1}\right) \square^{<0} \square^{51}-100 \square^{101}-200 \square^{201}-300 \square^{301}-400 \square^{401}-500 \square^{501}-650$ $\square$ No data

Fig. 6. Mean annual evapotranspiration from MODIS ET (MOD16) and MOD3T in 2008. Approximately 70\% of the MOD16 area has missing data. 


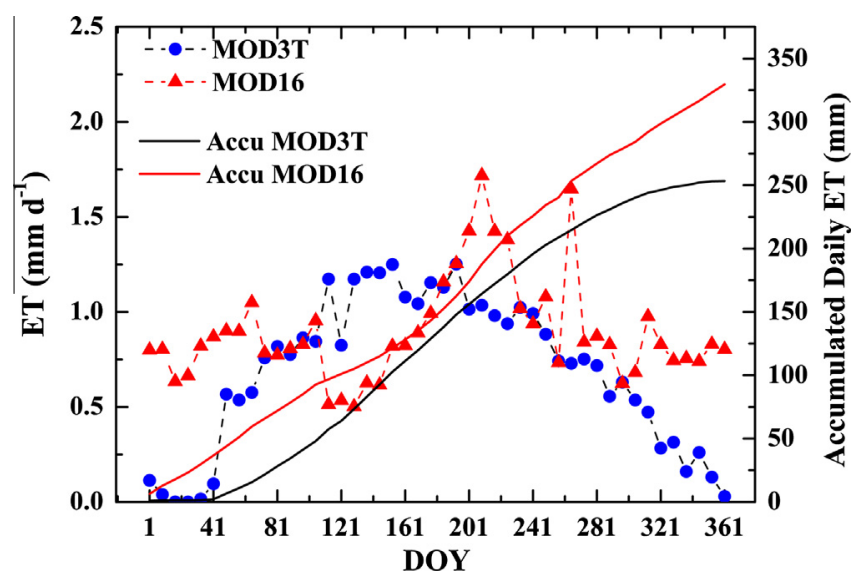

Fig. 8. Comparison of the ET in 2008 in the Heihe River Basin that is estimated by the two models (MOD16 and MOD3T). The cumulative values (solid line) are also provided.

For example, when $\left(T_{s}-T_{a}\right) /\left(T_{s r}-T_{a}\right)$ equals zero, the soil evaporation reaches its maximum value (the potential evaporation rate) indicating plenty of soil moisture; if $\left(T_{s}-T_{a}\right) /\left(T_{s r}-T_{a}\right)$ equals one, the soil evaporation reaches its minimum value (zero), indicating no soil moisture (Qiu et al., 2006). The results suggest that MOD3T is comparable to MOD16 in vegetated areas; however, at the basin scale, MOD16 results in ET with a greater uncertainty compared to MOD3T.

\subsection{Spatiotemporal distribution of the ET product}

Figs. 9 and 10 show the spatiotemporal distribution of the ET in the Heihe River Basin over 2008-2011. Fig. 9 indicates that (1) the modeled mean daily ET of each 8-day period varied from 0.00 to $2.19 \mathrm{~mm}$ over the four-year period, with mean values of 1.01 , $1.03,1.05$ and $1.06 \mathrm{~mm} \mathrm{~d}^{-1}$ in 2008, 2009, 2010 and 2011, respectively, and (2) temporally, the mean daily ET followed a sinusoidal variation each year. During winter, the ET values were lowest because the temperature was low and the vegetation was dormant. The ET during spring was higher than that during winter because the temperatures gradually increased and vegetation began to grow. The ET peaked during summer as a result of higher temperatures and better water conditions (summer precipitation accounted for approximately $80 \%$ of the annual precipitation). During autumn, the ET decreased as the temperatures dropped, and the vegetation growth slowed and ultimately stopped. The daily and seasonal ET suggested that the model results were correlated with the study area's climate.

The statistical results based on Fig. 10 showed that the mean annual ET of the Heihe River Basin was 260, 266, 271 and $272 \mathrm{~mm}$ in 2008, 2009, 2010 and 2011, respectively. Spatially, the ET gradually decreased from south to north (Fig. 10); that is, the ET decreased along a gradient starting in the southern mountains ( $>400 \mathrm{~mm} \mathrm{y}^{-1}$ ), where the vegetation coverage is abundant, and ending in the sparsely vegetated regions in the north $\left(<100 \mathrm{~mm} \mathrm{y}^{-1}\right)$. The southern part of the study area has a semiarid climate, whereas the northern part has an arid climate. Therefore, precipitation in the north was significantly lower than that in the south, leading to a higher ET in the south. This change is consistent with the regional climate and vegetation distribution.

\subsection{Partitioning the ET product into vegetation transpiration and soil evaporation}

In addition to ET, the vegetation transpiration $\left(E_{c}\right)$ (Fig. 11) and soil evaporation $\left(E_{s}\right)$ (Fig. 12) are provided in the proposed ET product. The inter-annual change in the Heihe River Basin in 2009 is included as an example (Fig. 13). With low vegetation cover, the vegetation transpiration only accounts for $15.41 \%$ of the total ET (annual value of $41 \mathrm{~mm}$ at the basin scale), whereas the soil evaporation has an annual value of $225 \mathrm{~mm}$. As discussed in Section 4, MOD3T produced similar values to the flux tower observations for barren/desert areas, where the ET is nearly entirely composed of soil evaporation, and for densely vegetated areas (maize), where transpiration accounts for a relative high percentage of the ET. Furthermore, Kang et al. (2005) reported that transpiration from

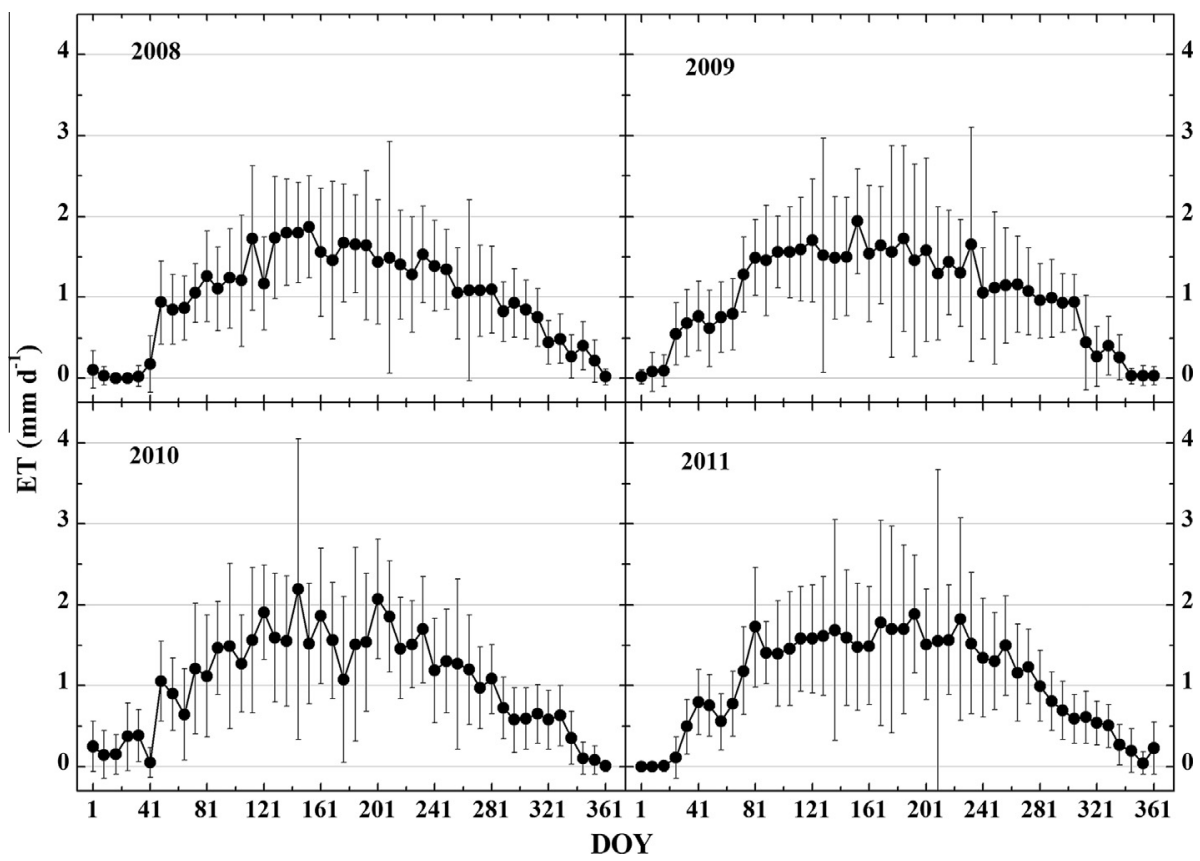

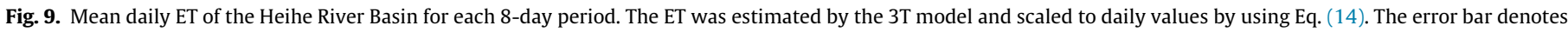
the standard deviation of the mean daily ET. 

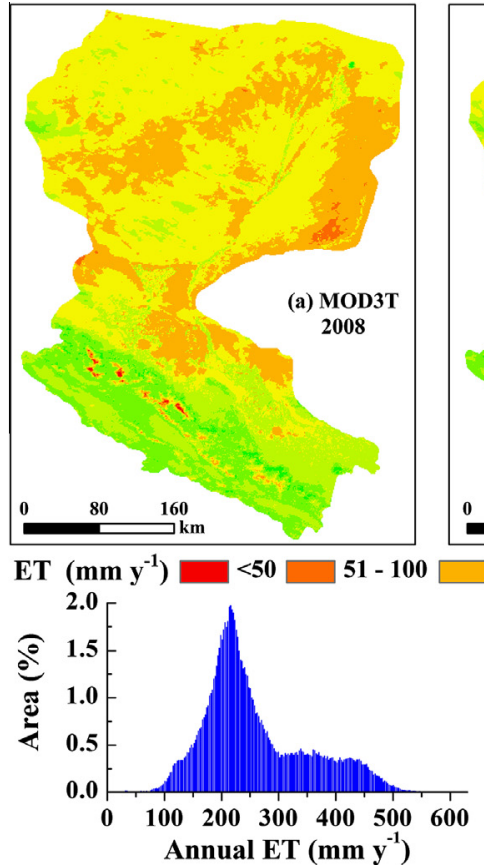
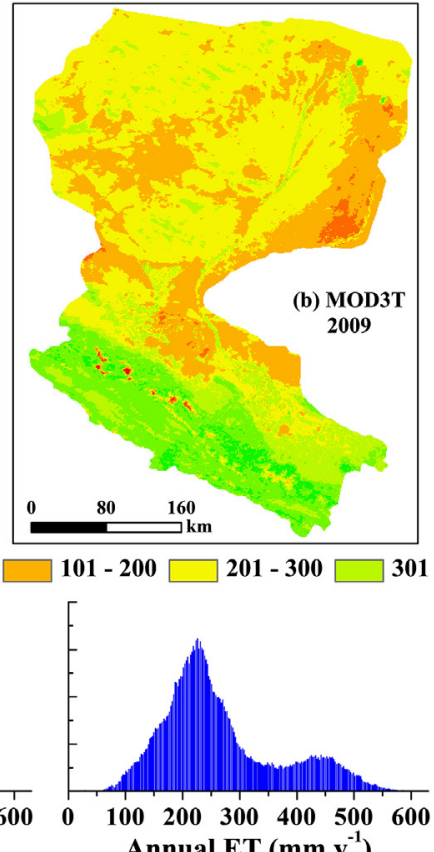
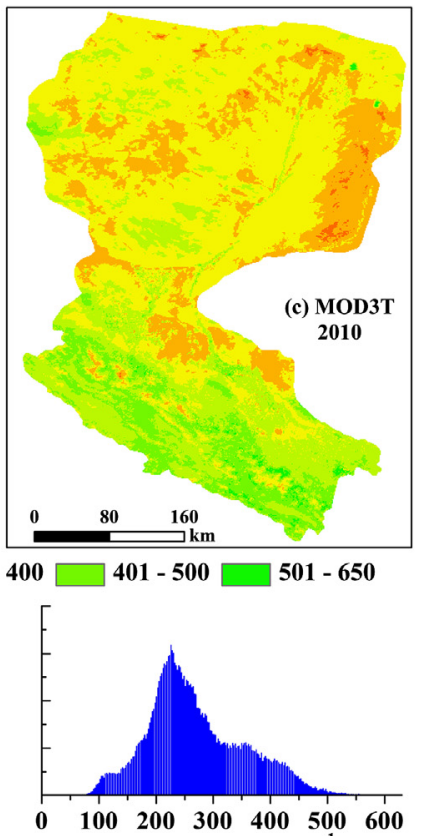

Annual ET (mm y $\left.\mathbf{~}^{-1}\right)$
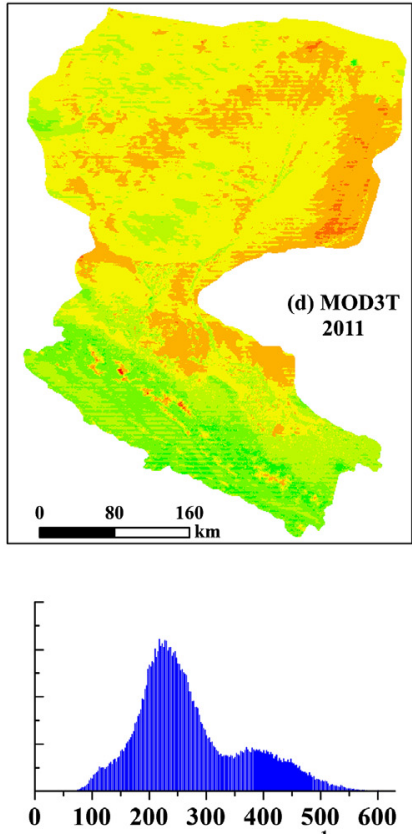

Annual ET ( $\left.\mathrm{mm} \mathrm{y}^{-1}\right)$

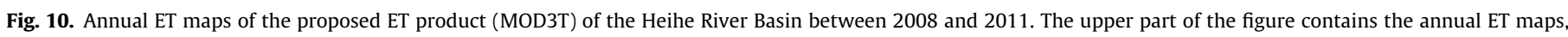
while the lower part contains histograms of the annual ET.
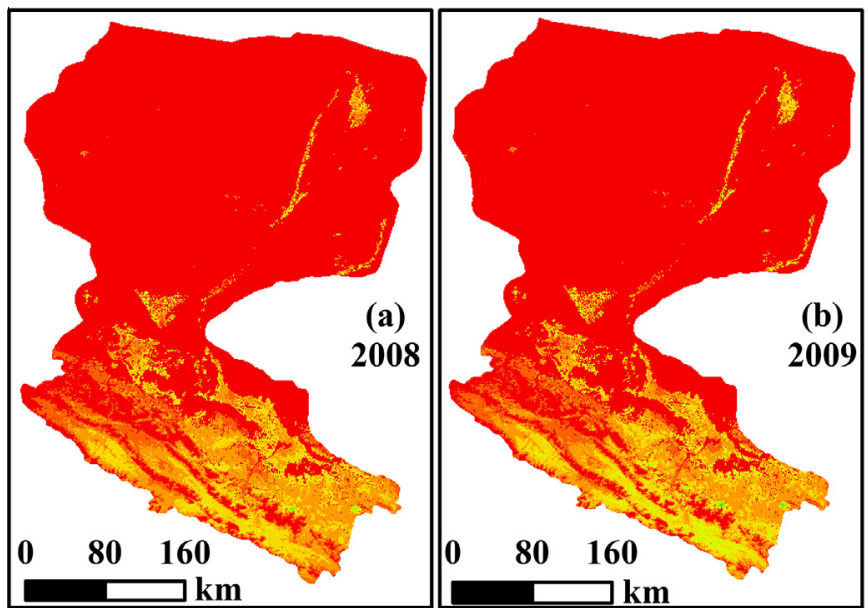

\section{$\operatorname{Ec}\left(\mathrm{mm} \mathrm{y}^{-1}\right)$}

$<\mathbf{5 0}$

$51-100$

$101-150$

$151-200$
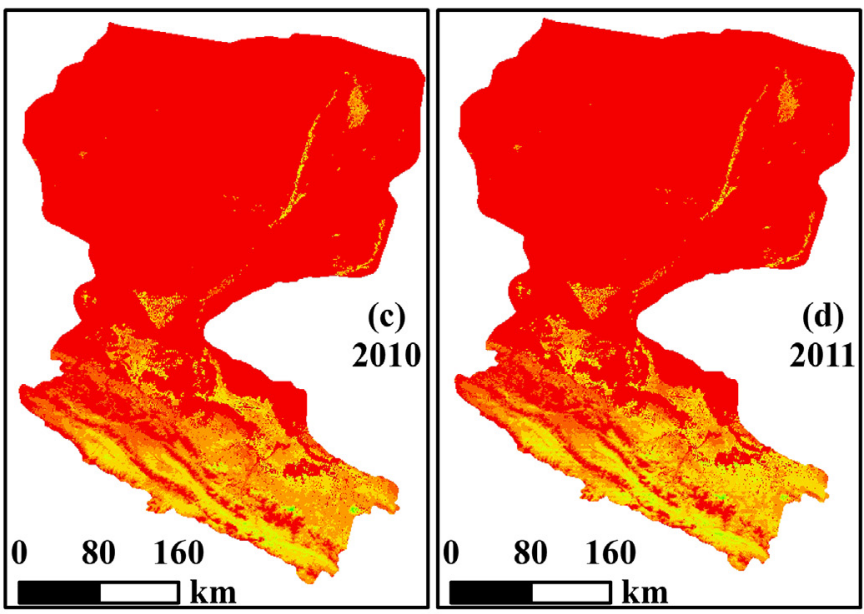

(d)

2011

Fig. 11. Annual vegetation transpiration $\left(E_{c}\right)$ in the Heihe River Basin between 2008 and 2011.

grasslands and forests (Picea crassifolia) in the mountainous areas of the Heihe River Basin (upper basin) accounted for 16\% and $47 \%$, respectively, of the evapotranspiration. In our study, the statistical results showed that the modeled vegetation transpiration in the upper basin accounted for $28 \%$ of the total ET (the ratio varied from $4 \%$ to $64 \%$ ) over the four-year period. Song et al. (2015) reported that the percentages of $E_{c}\left(E_{c} / \mathrm{ET}\right)$ and $E_{s}\left(E_{s} / \mathrm{ET}\right)$ based on stable oxygen and hydrogen isotopes were $84.3 \% \pm 5.2 \%$ and $15.7 \% \pm 5.2 \%$, respectively, at a maize field in the Daman Oasis during the 2012 growing season; these percentages were $60.4 \%$ and $39.6 \%$ in MOD3T (Fig. 14). Because the $E_{c} /$ ET $\left(E_{s} / \mathrm{ET}\right)$ values from MOD3T represented a large area $\left(9 \mathrm{~km}^{2}, 3 \times 3\right.$ pixels $)$, the ratios should be lower than the point-scale observations. In addition, the coarse resolution of MODIS is unable to accurately determine the fine-scale spatial structure of the land surface (McCabe and Wood, 2006), which may also contribute to bias in decomposing vegetation transpiration and soil evaporation. However, isotope approaches are often found to result in higher values for the percentage of $E_{c}\left(E_{c} / \mathrm{ET}\right)$, as summarized in Schlesinger and Jasechko (2014). Based on these results and the validation results that were presented in Section 4, the proposed ET components, although they must be tested further, can provide reasonable information for vegetation transpiration and soil evaporation.

\subsection{Possible biases in the proposed ET product}

Theoretically, the estimated ET product is valid for three natural surfaces-soil, vegetated areas and a combination thereof-accord- 


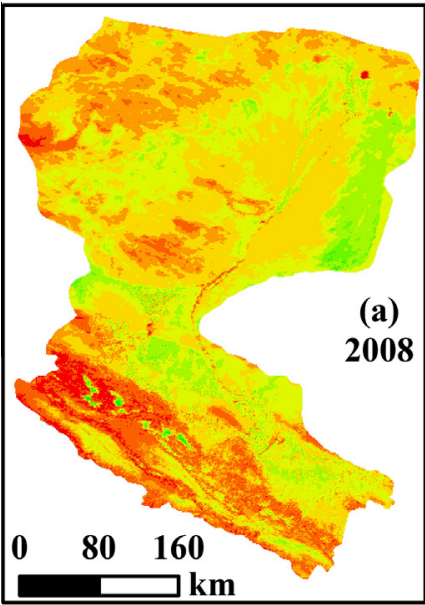

Es $\left(\mathrm{mm} \mathrm{y}^{-1}\right)$

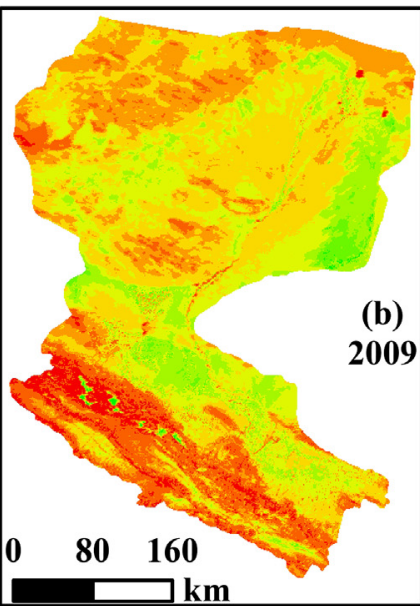

(b) 2009

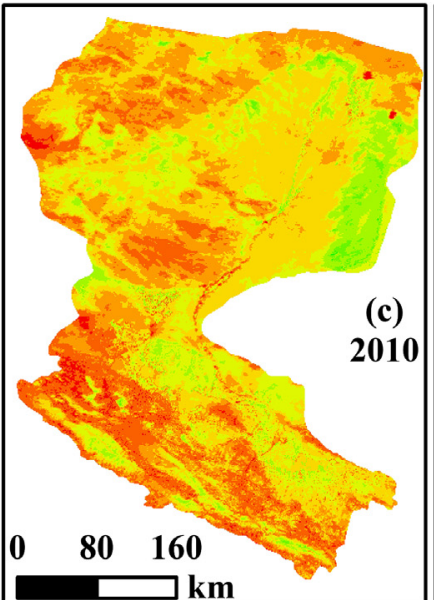

(c) 2010

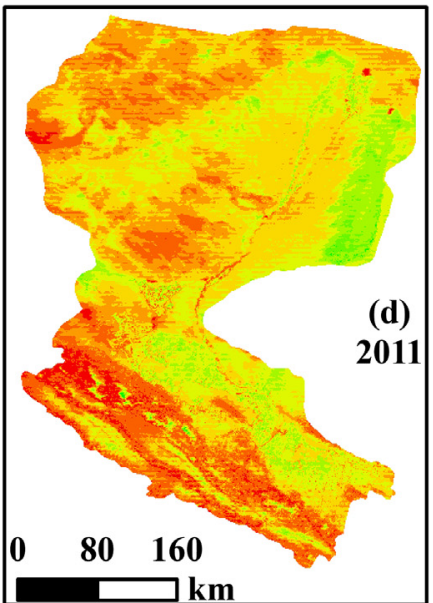

$\longrightarrow \mathbf{k m}$
$\square<\mathbf{5 0}$
$51-100$
$101-150$
$151-200$
$201-250$
$251-300$
$301-400$
$>400$

Fig. 12. Annual soil evaporation $\left(E_{s}\right)$ in the Heihe River Basin between 2008 and 2011

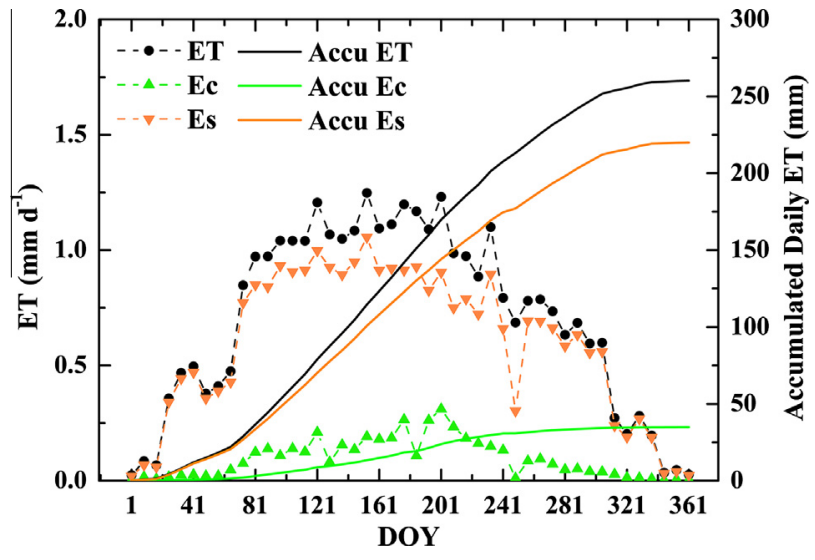

Fig. 13. Inter annual change in the proposed ET product and its two components $\left(E_{c}\right.$ and $E_{s}$ ) in the Heihe River Basin in 2009. The cumulative values (solid line) are also provided.

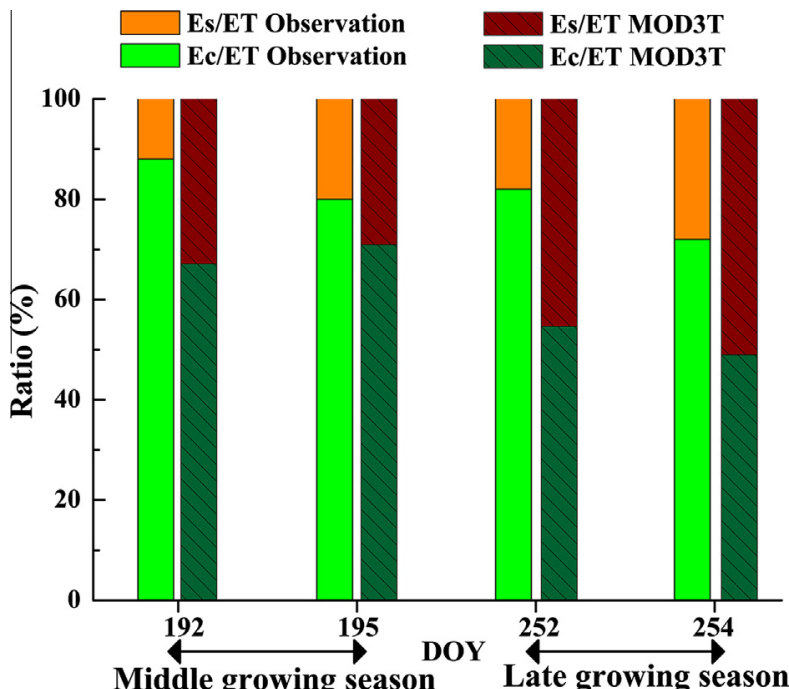

Fig. 14. Comparison of the ratios of $E_{c}\left(E_{c} / \mathrm{ET}\right)$ and $E_{s}\left(E_{s} / \mathrm{ET}\right)$ between MOD3T ( $3 \times 3$ pixels) and observations in a maize field within the Daman Oasis during the 2012 growing season. The observed ratio was calculated by using the stable oxygen and hydrogen isotopes near an eddy flux tower (Song et al., 2015). ing to the formulation of the 3T model. Therefore, our product cannot produce ET over water surfaces or urban/built-up areas. In arid regions, surface water, such as lakes and rivers, is scarce. For example, water surfaces only cover $3.48 \%$ of our study area according to the MOD12Q1 land cover type 2. The estimated ET for water surfaces may be incorrect, but this finding has little impact on the estimates for the entire basin. At a spatial resolution of $1 \mathrm{~km}$, urban/built-up areas may be ignored, and ET estimations for such areas are difficult. Although our ET product is not valid for all natural surfaces, it can provide useful information for soil, vegetated areas or any combination thereof.

In this study, flux tower observations were lacking; thus, data from only two flux towers were adopted for validation. Although some of the modeled and observed ET values were similar, particular differences were observed (see Section 3.4 for details). The validation of the MOD3T product should be thoroughly tested in future studies by using additional ground observation data.

Biases in ET estimations may be caused by numerous factors (e.g., Mu et al., 2011; Velpuri et al., 2013; Long et al., 2014), such as model/algorithm limitations, model parameterizations, ground-based observation errors (e.g., flux tower measurements errors), MODIS pixel spatial heterogeneity and mismatches between pixels and the flux tower footprint. Therefore, we address the possible limitations of the $3 \mathrm{~T}$ model and model parameterization.

First, ET may be overestimated by the 3T model. When introducing the reference surface temperature to circumvent the aerodynamic resistance $\left(r_{a}\right)$, the 3T model assumed that the $r_{a}$ of a drying surface (soil or vegetated area) was equal to that of a dry surface (dry soil without evaporation or a canopy without transpiration) (see Qiu, 1996; Qiu et al., 1996, 1998 for details). However, the $r_{a}$ of a drying surface is often larger than the $r_{a}$ of a dry surface. This overestimation can be seen in Fig. 4: the ET that was estimated by the $3 \mathrm{~T}$ model was higher than that of the observations in most cases.

Second, to simplify the 3T model for remote sensing applications, the reference temperatures $\left(T_{s r}\right.$ and $\left.T_{c r}\right)$ in the 3T-S model were replaced with a regional maximum value for the soil surface temperature $\left(T_{s, \max }\right)$ and vegetation temperature $\left(T_{c, \max }\right)$, respectively, over an available region size, as shown in Eqs. (6) and (7). As discussed in our previous research (Xiong and Qiu, 2014), the region size may affect the maximum temperature based on an analysis of six areas of decreasing size in a TM image. The results 
showed that $T_{s, \max }$ was much more sensitive to the region size than $T_{c, \max }$. The maximum difference between the six $T_{s, \max }$ values was $8.8 \mathrm{~K}$, whereas it was $2.8 \mathrm{~K}$ for $T_{c, \text { max }}$. However, the maximum difference between the modeled ET values was $0.54 \mathrm{~mm}$. Compared with the flux tower ET, the MAPEs varied from $4.13 \%$ to $20.8 \%$, with a mean value of $11.9 \%$. This type of uncertainty is called the domain dependence in satellite-based ET estimation (Long et al., 2011). Our previous analysis (Xiong and Qiu, 2014) suggested that the 3T model could suffer from domain dependence if the reference temperatures are replaced with the maximum temperatures method, and a minimum domain size of $9600 \mathrm{~km}^{2}$ (approximately $3 \times 10^{8}$ times the TM pixel size) was required to obtain reasonable model accuracy. In this study, the domain size is $403398 \mathrm{~km}^{2}$ $\left(614 \times 657\right.$ pixels, approximately $4 \times 10^{8}$ times the MODIS pixel size). Even if a large study domain may break down the assumption of the maximum temperatures method and cause uncertainty in the ET estimate, the validation results of this study indicate that the $3 \mathrm{~T}$ model is reliable when applied to an area of approximately $400000 \mathrm{~km}^{2}$. In addition, the pixel with the maximum surface temperature within a satellite image is most likely a dry soil surface; however, identifying a canopy without transpiration (dry canopy) can be difficult, and dry conditions can be affected by precipitation. Therefore, simplified parameterization might create risks that affect the modeled ET and lead to biases.

Third, the parameterization of the model inputs may cause errors in addition to the uncertainties in the MODIS products (e.g., LST, LAI and FPAR), as summarized in Mu et al. (2011). Our previous uncertainty analysis showed that the estimated ET from the $3 \mathrm{~T}$ model is not sensitive to most parameters, even if a parameter has an uncertainty of $\pm 10 \%$. Additionally, the modeled ET is more sensitive to the four input parameters, i.e., net radiation $\left(R_{n}\right)$, soil temperature $\left(T_{s}\right)$, vegetation temperature $\left(T_{c}\right)$, and air temperature $\left(T_{a}\right)$, which each have an uncertainty of $\pm 10 \%$ (Xiong and Qiu, 2011). The algorithm that was adopted to parameterize $T_{s}$ and $T_{c}$, which are the soil and canopy component temperatures, respectively, may cause uncertainties because Eq. (11) contains empirical coefficients that may be unsuitable for all land surfaces. However, the uncertainty that is caused by the above factors is likely counteracted by the difference ratio in Eq. (1) or (2) (e.g., $\left(T_{s}-T_{a}\right) /\left(T_{s r}-T_{a}\right)$ ), as shown in our previous study (Qiu et al., 2006; Xiong and Qiu, 2014) and in Sun et al. (2009), who used a revised 3T model (Sim-ReSET model). In our study, the net radiation is estimated by using the MODIS LST and air temperature; the uncertainties that are associated with these two variables, particularly the air temperature, may cause errors. Because of data availability, using the daily average air temperature would cause uncertainty because the air temperature at the satellite overpass time (i.e., when the MODIS LST is recorded) is required as model input. Because the MODIS LST product is a combination of the best quality LSTs from a certain day during eight days and because obtaining the synchronous air temperature for these pixels at different times and dates is a challenge, the asynchronicity between instantaneous LSTs and daily mean air temperatures can impact the performance of the 3T model. The MAPE between our model estimation and observation is $18.53 \%$ when using the daily MODIS LST (MOD11A1) and synchronous air temperature as model inputs, whereas the value is $24.87 \%$ when using the 8 -day MODIS LST (MOD11A2) and asynchronous daily mean air temperature as model inputs. Therefore, the methods that are adopted to parameterize the model input should be carefully selected based on the study requirements and data availability.

Furthermore, scaling remotely sensed instantaneous ET to daily or 8-day values may contribute to the uncertainties. Chávez et al. (2008) suggested that the extrapolation methods that are used to estimate the daily ET from instantaneous values can create errors that vary from $-5.7 \pm 4.8 \%$ to $26.0 \pm 15.8 \%$ (mean bias error \pm root mean square error). In addition, when the daily ET value was scaled to an 8-day value, only the cloudy coefficient $\left(a_{C}\right)$, including the cloud cover and number of sunny days, was considered (Eq. (15)). Because of the data availability in this study, $a_{C}$ was obtained by interpolating the mean annual values for the period from 1981 to 2010 . The statistical results show that the mean value of $a_{C}$ was 0.70 . For example, if $a_{C}$ changes from 0.7 to 0.80 in 2008, then the mean annual ET for the Heihe River Basin increases from $260 \mathrm{~mm}$ to $297 \mathrm{~mm}$ and the MAPE decreases from $8.85 \%$ to $4.12 \%$. Thus, the absence of other important parameters, such as wind speed, may have caused uncertainties.

\section{Conclusions}

The objective of this study was to develop an evapotranspiration product (MOD3T) for arid regions by using thermal remote sensing data. The 3T model, which was based on an energy balance equation that does not include resistance, was used to generate instantaneous ET values. The MODIS datasets, i.e., MODIS land surface temperature/emissivity data (MOD11A2), LAI and FPAR data (MOD15A2), global MODIS vegetation indices (MOD13A2), and albedos (MCD43B3), could provide all of the model input that is required for the $3 \mathrm{~T}$ model except for air temperature. The instantaneous ET was extrapolated to a daily value based on a sinusoidal function for cloudless days that was proposed by Jackson et al. (1983). We then summed the daily ET into 8-day values by considering cloud effects. Finally, the 8-day and annual ET products, including soil evaporation and vegetation transpiration, were produced with a 1-km resolution over three natural surfaces: soil, vegetated areas and a combination of both.

A case study was performed in two adjacent inland river basins in the arid and cold region of northwestern China from 2008 to 2012. The proposed ET product was evaluated in two ways. First, the modeled ET was compared to the flux tower ET at a daily scale. The results showed that the MAE (MAPE) values were $0.71 \mathrm{~mm} \mathrm{~d}^{-1}$ (18.53\%) and $0.16 \mathrm{~mm} \mathrm{~d}^{-1}(24.87 \%)$ for dense maize and a sparsely vegetated sandy desert, respectively. Second, the proposed ET product was compared with the water balance ET at an annual scale. The results showed that the MAE (MAPE) was $23.76 \mathrm{~mm} \mathrm{y}^{-1}$ $(8.06 \%)$ over the four year period. Although differences were observed between the estimations and observations, the results suggest that the $3 \mathrm{~T}$ model was able to produce ET within acceptable limits.

Furthermore, our ET product has several advantages. Unlike the currently available ET product (MOD16), the proposed ET product can provide ET values and an optional ET algorithm and product for barren/desert areas. In addition, the product for the soil evaporation and vegetation transpiration components of a given pixel can be generated with reasonable accuracy to obtain detailed information for practical applications, such as water resource management. A future step is to thoroughly test our ET product in combination with additional flux ET observations from towers that are installed in various ecosystems.

\section{Acknowledgements}

This study was supported by the National Natural Science Foundation of China (Nos. 41201433, 91025008 and 41101313), the Specialized Research Fund for the Doctoral Program of Higher Education of China (No. 20110171120001), and the National Basic Research Program (973 Program) (No. 2009CB421303). We thank the China Meteorological Administration for providing meteorological data, the Heihe Watershed Applied Telemetry Experimental Research (HiWATER) project for providing flux ET, and NASA for 
providing the MODIS datasets. We are grateful to the reviewers and editor for their insightful and constructive comments.

\section{References}

Allen, R.G., Pereira, L.S., Howell, T.A., Jensen, M.E., 2011. Evapotranspiration information reporting: I. Factors governing measurement accuracy. Agric. Water Manage. 98, 899-920.

Allen, R.G., Pereira, L.S., Raes, D., Smith, M., 1998. Crop evapotranspiration guidelines for computing crop water requirements. FAO Irrigation and Drainage Paper 56. Food and Agriculture Organization of the United Nations, Rome, Italy. <http://www.fao.org/docrep/X0490E/X0490E00.htm> (accessed 22.06.15).

Allen, R.G., Tasumi, M., Trezza, R., 2007. Satellite-based energy balance for mapping evapotranspiration with internalized calibration (METRIC)-model. J. Irrig. Drain. Eng. 133 (4), 395-406.

Anderson, M., Norman, J., Kustas, W., Houborg, R., Starks, P., Agam, N., 2008. A thermal-based remote sensing technique for routine mapping of land-surface carbon, water and energy fluxes from field to regional scales. Remote Sens. Environ. 112 (12), 4227-4241.

Baldocchi, D.D., 2003. Assessing the eddy covariance technique for evaluating carbon dioxide exchange rates of ecosystems: past, present and future. Global Change Biol. 9, 479-492.

Bastiaanssen, W.G.M., Menenti, M., Feddes, R.A., Holtslag, A.A.M., 1998. A remote sensing surface energy balance algorithm for land (SEBAL) 1. Formulation. J. Hydrol. 212-213, 198-212.

Bastiaanssen, W.G.M., Noordman, E.J.M., Pelgrum, H., Davids, G., Thoreson, B.P., Allen, R.G., 2005. SEBAL model with remotely sensed data to improve water resources management under actual field conditions. J. Irrig. Drain. Eng. 131 (1), $185-193$.

Bowen, I.S., 1926. The ratio of heat losses by conduction and evaporation from any water surface. Phys. Rev. 27 (6), 779-798.

Carlson, T.N., Capehart, W.J., Gillies, R.R., 1995. A new look at the simplified method for remote sensing of daily evapotranspiration. Remote Sens. Environ. 54, 161167.

Chávez, J.L., Neale, C.M.U., Prueger, J.H., Kustas, W.P., 2008. Daily evapotranspiration estimates from extrapolating instantaneous airborne remote sensing ET values. Irrig. Sci. 27 (1), 67-81.

Chen, Y., Zhang, D.Q., Sun, Y.B., Liu, X.N., Wang, N.Z., Savenije, H.H.G., 2005. Wate demand management: A case study of the Heihe River Basin in China. Phys. Chem. Earth 30 (6-7), 408-419.

Cheng, L., Xu, Z., Wang, D., Cai, X., 2011. Assessing interannual variability of evapotranspiration at the basin scale using satellite-based evapotranspiration datasets. Water Resour. Res. 47, W09509. http://dx.doi.org/10.1029/ 2011WR010636.

Cleugh, H.A., Leuning, R., Mu, Q., Running, S.W., 2007. Regional evaporation estimates from flux tower and MODIS satellite data. Remote Sens. Environ. 106, $285-304$.

Dirmeyer, P.A., Gao, X., Zhao, M., Guo, Z., Oki, T., Hanasaki, N., 2006. GSWP-2: multimodel analysis and implications for our perception of the land surface. Bull. Am. Meteorol. Soc. 87, 1381-1397.

Dodds, P., Meyer, W., Barton, A., 2005. A review of methods to estimate irrigated reference crop evapotranspiration across Australia. Technical report 04/05, CRC for irrigation futures and CSIRO land and water, Adelaide, South Australia.

Falkenmark, M., Rockstrom, J., 2004. Balancing Water for Humans and Nature: The New Approach in Ecohydrology. Earthscan Press, London.

Feng, X.M., Sun, G., Fu, B.J., Su, C.H., Liu, Y., Lamparski, H., 2012. Regional effects of vegetation restoration on water yield across the Loess Plateau, China. Hydrol. Earth Syst. Sci. 16, 2617-2628.

Glenn, E.P., Huete, A.R., Nagler, P.L., Hirschboeck, K.K., Brown, P., 2007. Integrating remote sensing and ground methods to estimate evapotranspiration. Crit. Rev. Plant Sci. 26 (3), 139-168.

Heim Jr., R.R., 2002. A review of twentieth-century drought indices used in the United States. Bull. Am. Meteorol. Soc. 83, 1149-1165.

Jackson, R.D., Hatfield, J.L., Reginato, R.J., Idso, S.B., Pinter, P.J., 1983. Estimation of daily evapotranspiration from one time-of-day measurements. Agric. Water Manage. 7, 351-362.

Jarvis, A., Reuter, H.I., Nelson, A., Guevara, E., 2008. Hole-filled SRTM for the globe version 4, available from the CGIAR-CSI SRTM 90m Database at http://srtm.csi. cgiar.org.

Jia, L., Su, Z., van den Hurk, B., Menenti, M., Moene, A., De Bruin, H., Yrisarry, J. Ibanez, M., Cuesta, A., 2003. Estimation of sensible heat flux using the surface energy balance system (SEBS) and ATSR measurements. Phys. Chem. Earth, Parts A/B/C 28, 75-88.

Jung, M., Reichstein, M., Ciais, P., Seneviratne, S.I., Sheffield, J., Goulden, M.L., Bonan, G. Cescatti, A., Chen, J., de Jeu, R., Dolman, H., Eugster, W., Gerten, D., Gianelle, D., Gobron, N., Heinke, J., Kimball, J., Law, B.E., Montagnani, L., Mu, Q., Mueller, B., Oleson, K., Papale, D., Richardson, A.D., Roupsard, O., Running, S., Tomelleri, E., Viovy, N., Weber, U., Williams, C., Wood, E., Zaehle, S., Zhang, K., 2010. A recent slowdown in global land evapotranspiration due to limited moisture supply. Nature 467, 951.

Kang, E., Cheng, G., Song, K., Jin, B., Liu, X., Wang, J., 2005. Simulation of energy and water balance in Soil-Vegetation-Atmosphere Transfer system in the mountain area of Heihe River basin at Hexi Corridor of northwest China. Sci. China, Ser. D: Earth Sci. 48 (4), 538-548.
Kothavala, Z., Arain, M.A., Black, T.A., Verseghy, D., 2005. The simulation of energy, water vapor and carbon dioxide fluxes over common crops by the Canadian Land Surface Scheme (CLASS). Agric. For. Meteorol. 133, 89-108.

Kustas, W.P., Daughtry, C.S.T., 1990. Estimation of the soil heat flux/net radiation ratio from spectral data. Agric. For. Meteorol. 49, 205-223.

Kustas, W.P., Norman, J.M., 1999. Evaluation of soil and vegetation heat flux predictions using a simple two-source model with radiometric temperatures for partial canopy cover. Agric. For. Meteorol. 94, 13-29.

Law, B.E., Falge, E., Gu, L., Baldocchi, D.D., Bakwin, P., Berbigier, P., Davis, K., Dolman, A.J., Falk, M., Fuentes, J.D., Goldstein, A., Granier, A., Grelle, A., Hollinger, D., Janssens, I.A., Jarvis, P., Jensen, N.O., Katul, G., Mahli, Y., Matteucci, G., Meyers, T., Monson, R., Munger, W., Oechel, W., Olson, R., Pilegaard, K., Paw, K.T., Thorgeirsson, H., Valentini, R., Verma, S., Vesala, T., Wilson, K., Wofsy, S., 2002. Environmental controls over carbon dioxide and water vapor exchange of terrestrial vegetation. Agric. For. Meteorol. 113, 97-120.

Lhomme, J.-P., Monteny, B., Amadou, M., 1994. Estimating sensible heat flux from radiometric temperature over sparse millet. Agric. For. Meteorol. 68, 77-91.

Li, F., Kustas, W.P., Prueger, J.H., Neale, C.M.U., Jackson, J.J., 2005. Utility of remote sensing based two-source energy balance model under low and high vegetation cover conditions. J. Hydrometeorol. 6, 878-891.

Li, X., Cheng, G.D., Liu, S.M., Xiao, Q., Ma, M.G., Jin, R., Che, T., Liu, Q.H., Wang, W.Z., Qi, Y., Wen, J.G., Li, H.Y., Zhu, G.F., Guo, J.W., Ran, Y.H., Wang, S.G., Zhu, Z.L., Zhou, J., Hu, X.L., Xu, Z.W., 2013. Heihe Watershed Allied Telemetry Experimental Research (HiWATER): scientific objectives and experimental design. Bull. Am. Meteorol. Soc. http://dx.doi.org/10.1175/BAMS-D-12-00154.

Li, X., Li, X.W., Li, Z.Y., Ma, M.G., Wang, J., Xiao, Q., Liu, Q.H., Che, T., Chen, E.X., Yan, G. J., Hu, Z.Y., Zhang, L.X., Chu, R.Z., Su, P.X., Liu, Q.H., Liu, S.M., Wang, J.D., Niu, Z., Chen, Y., Jin, R., Wang, W.Z., Xin, Z.Z., Ren, H.Z., 2009a. Watershed allied telemetry experimental research. J. Geophys. Res. 114, D22103. http://dx.doi. org/10.1029/2008JD011590.

Li, Z.L., Tang, R., Wan, Z., Bi, Y., Zhou, C., Tang, B., Yan, G., Zhang, X., 2009b. A review of current methodologies for regional evapotranspiration estimation from remotely sensed data. Sensors 9 (5), 3801-3853.

Liu, S.M., Xu, Z.W., Wang, W.Z., Bai, J., Jia, Z., Zhu, M., Wang, J.M., 2011. A comparison of eddy-covariance and large aperture scintillometer measurements with respect to the energy balance closure problem. Hydrol. Earth Syst. Sci. 15 (4), 1291-1306.

Loarie, S.R., Lobell, D.B., Asner, G.P., Mu, Q., Field, C.B., 2011. Direct impacts on local climate of expanding sugarcane in Brazil. Nat. Climate Change 1, 105-109.

Long, D., Singh, V.P., Li, Z.L., 2011. How sensitive is SEBAL to changes in input variables, domain size and satellite sensor? J. Geophys. Res. - Atmos. 116, D21107. http://dx.doi.org/10.1029/2011JD016542.

Long, D., Longuevergne, L., Scanlon, B.R., 2014. Uncertainty in evapotranspiration from land surface modeling, remote sensing, and GRACE satellites. Water Resour. Res. 50, 1131-1151.

Long, D., Singh, V.P., 2013. Assessing the impact of end-member selection on the accuracy of satellite-based spatial variability models for actual evapotranspiration estimation. Water Resour. Res. 49, 2601-2618. http://dx. doi.org/10.1002/wrcr.20208.

Los, S.O., Collatz, G.J., Sellers, P.J., Malmstrom, C.M., Pollack, N.H., DeFries, R.S. Bounoua, L., Dazlich, D.A., 2000. A global 9-yr biophysical land surface dataset from NOAA AVHRR data. J. Hydrometeorol. 1 (2), 183-199.

Matsushita, B. Fukushima, T, 2009. Methods for retrieving hydrologically significant surface parameters from remote sensing: a review for applications to East Asia region. Hydrol. Process. 23 (4), 524-533.

McCabe, M.F. Wood, E.F., 2006. Scale influences on the remote estimation of evapotranspiration using multiple satellite sensors. Remote Sens. Environ. 105 (4), 271-285.

Monteith, J.L., 1973. Principles of Environmental Physics, second ed. Edward Arnold Press, London.

Moran, M.S., Jackson, R.D., Raymond, L.H., Gay, L.W., Slater, P.N., 1989. Mapping surface energy balance components by combining landsat thematic mapper and ground-based meteorological data. Remote Sens. Environ. 30, 77-87.

Mu, Q., Heinsch, F.A., Zhao, M., Running, S.W., 2007. Development of a global evapotranspiration algorithm based on MODIS and global meteorology data. Remote Sens. Environ. 111, 519-536.

Mu, Q., Zhao, M., Kimball, J.S., McDowell, N.G., Running, S.W., 2013. A remotely sensed global terrestrial drought severity index. Bull. Am. Meteorol. Soc. 94, 8398.

Mu, Q., Zhao, M., Running, S.W., 2011. Improvements to a MODIS global terrestrial evapotranspiration algorithm. Remote Sens. Environ. 115, 1781-1800.

Nemani, R., White, M., Thornton, P., Nishida, K., Reddy, S., Jenkins, J., Running, S., 2002. Recent trends in hydrologic balance have enhanced the terrestrial carbon sink in the United States. Geophys. Res. Lett. 29 (10), 1468.

Norman, J.M., Kustas, W.P., Humes, K.S., 1995. Source approach for estimating soil and vegetation energy fluxes in observations of directional radiometric surface temperature. Agric. For. Meteorol. 77, 263-293.

Oki, T., Kanae, S., 2006. Global hydrological cycles and world water resources. Science 313 (5790), 1068-1072.

Pielke, R., Avissar, R., Raupach, M., Dolman, A.J., Zeng, X., Denning, A.S., 1998 Interactions between the atmosphere and terrestrial ecosystems: influence on weather and climate. Global Change Biol. 4, 461-475.

Priestley, C.H.B., Taylor, R.J., 1972. On the assessment of surface heat flux and evaporation using large-scale parameters. Mon. Weather Rev. 100, 81-82.

Qi, S.Z., Luo, F., 2005. Water demand management - a case study of the Heihe River Basin. Environ. Monit. Assess. 108, 205-215. 
Qin, J., Ding, Y.J., Yang, G.J., 2013. The hydrological linkage of mountains and plains in the arid region of northwest China. Chin. Sci. Bull. 58, 3140-3147.

Qiu, G.Y., 1996. A new method for estimation of evapotranspiration. Doctoral dissertation, the Unite Graduate School of Agricultural Science, Tottori University, Japan.

Qiu, G.Y., Li, C., Yan, C.H., 2015. Characteristics of soil evaporation, plant transpiration and water budget of Nitraria dune in the arid Northwest China. Agric. For. Meteorol. 203, 107-117.

Qiu, G.Y., Shi, P.J., Wang, L.M., 2006. Theoretical analysis of a soil evaporation transfer coefficient. Remote Sens. Environ. 101, 390-398.

Qiu, G.Y., Yano, T., Momii, K., 1998. An improved methodology to measure evaporation from bare soil based on comparison of surface temperature with a dry soil. J. Hydrol. 210, 93-105.

Qiu, G.Y., Yano, T., Momii, K., 1996. Estimation of plant transpiration by imitation leaf temperature. I. Theoretical consideration and field verification. Trans. Jpn. Soc. Irrig., Drain. Reclam. Eng. 64, 401-410.

Schlesinger, W.H., Jasechko, S., 2014. Transpiration in the global water cycle. Agric. For. Meteorol. 189-190, 115-117.

Scott, R.L., Shuttleworth, W.J., Goodrich, D.C., Maddock, T., 2000. The water use of two dominant vegetation communities in a semiarid riparian ecosystem. Agric. For. Meteorol. 105, 241-256.

Shi, Y.F., Shen, Y.P., Kang, E.S., Li, D.L., Ding, Y.J., Zhang, G.W., Hu, R.J., 2007. Recent and future climate change in Northwest China. Climatic Change 80 (3-4), 379393. http://dx.doi.org/10.1007/s10584-006-9121-7.

Shuttleworth, W.J., Wallace, J.S., 1985. Evaporation from sparse crops - an energy combination theory. Quart. J. Roy. Meteorol. Soc. 111, 839-855.

Sobrino, J.A., Raissouni, N., Li, Z.L., 2001. A comparative study of land surface emissivity retrieval from NOAA data. Remote Sens. Environ. 75, 256-266.

Sobrino, J.A., Jimenez-munoz, J.C., Paolini, L., 2004. Land surface temperature retrieval from LANDSAT TM 5. Remote Sens. Environ. 90, 434-440.

Song, L.S., Liu, S.M., Zhang, X., Zhou, J., Li, M.S., 2015. Estimating and validating soil evaporation and crop transpiration during the HiWATER-MUSOEXE. IEEE Geosci. Remote Sens. Lett. 12 (2), 334-338. http://dx.doi.org/10.1109/ LGRS.2014.2339360.

Su, Z., 2002. The surface energy balance system (SEBS) for estimation of the turbulent heat fluxes. Hydrol. Earth Sci. 6 (1), 85-99.

Sun, Z., Wang, Q., Matsushita, B., Fukushima, T., Ouyang, Z., Watanabe, M., 2009. Development of a simple remote sensing evapotranspiration model (SimReSET): algorithm and model test. J. Hydrol. 376 (3-4), 476-485.

Swinbank, W.C., 1963. Long-wave radiation from clear skies. Quart. J. Roy. Meteorol. Soc. $89,339-348$.

Teuling, A.J., Hirschi, M., Ohmura, A., Wild, M., Reichstein, M., Ciasis, P., Buchmann, N., Ammann, C., Montagnani, L., Richardson, A.D., Wohlfahrt, G., Seneviratne, S. I., 2009. A regional perspective on trends in continental evaporation. Geophys. Res. Lett. 36, L02404.

Tian, F., Qiu, G.Y., Lü, Y.H., Yang, Y.H., Xiong, Y.J., 2014. Use of high-resolution thermal infrared remote sensing and "three-temperature model" for transpiration monitoring in arid inland river basin. J. Hydrol. 515, 307-315. http://dx.doi.org/10.1016/j.jhydrol.2014.04.056.

Tian, F., Qiu, G.Y., Yang, Y.H., Lü, Y.H., Xiong, Y.J., 2013. Estimation of evapotranspiration and its partition based on an extended three-temperature model and MODIS products. J. Hydrol. 498, 210-220.

Trenberth, K.E., Smith, L., Qian, T., Dai, A., Fasullo, J., 2007. Estimates of the global water budget and its annual cycle using observational and model data. J. Hydrometeorol. 8, 758-769.

Velpuri, N.M., Senay, G.B., Singh, R.K., Bohms, S., Verdin, J., 2013. A comprehensive evaluation of two MODIS evapotranspiration products over the conterminous United States: using point and gridded FLUXNET and water balance ET. Remote Sens. Environ. 139, 35-49.

Vinukollu, R.K., Wood, E.F., Ferguson, C.R., Fisher, J.B., 2011. Global estimates of evapotranspiration for climate studies using multi-sensor remote sensing data: evaluation of three process-based approaches. Remote Sens. Environ. 115 (3), 801-823.

Wang, G., Liu, J., Kubota, J., Chen, L., 2007. Effects of land-use changes on hydrological processes in the middle basin of the Heihe River, northwest China. Hydrol. Process. 21, 1370-1382.
Wang, K.C., Dickinson, R.E., 2012. A review on global terrestrial evapotranspiration: observation, modeling, climatology, and climatic variability. Rev. Geophys. 50, RG2005. http://dx.doi.org/10.1029/2011RG000373.

Wang, S., 2008. Simulation of evapotranspiration and its response to plant water and $\mathrm{CO}_{2}$ transfer dynamics. J. Hydrometeorol. 9, 426-443. http://dx.doi.org/ 10.1175/2007JHM918.1.

Wang, S., Huang, J., Li, J., Rivera, A., McKenney, D.W., Sheffield, J., 2014a. Assessment of water budget for sixteen large drainage basins in Canada. J. Hydrol. 512, 115. http://dx.doi.org/10.1016/j.jhydrol.2014.02.058.

Wang, S., McKenney, D.W., Shang, J., Li, J., 2014b. A national-scale assessment of long-term water budget closures for Canada's watersheds. J. Geophys. Res. Atmos. 119, 8712-8725. http://dx.doi.org/10.1002/2014JD021951.

Wang, S., Yang, Y., Luo, Y., Rivera, A., 2013. Spatial and seasonal variations in evapotranspiration over Canada's landmass. Hydrol. Earth Syst. Sci. 17, $3561-$ 3575. http://dx.doi.org/10.5194/hess-17-3561-2013.

Xiong, Y.J., Qiu, G.Y., 2011. Estimation of evapotranspiration using remotely sensed land surface temperature and the revised three-temperature model. Int. J. Remote Sens. 32 (20), 5853-5874.

Xiong, Y.J., Qiu, G.Y., 2014. Simplifying the revised three-temperature model for remotely estimating regional evapotranspiration and its application to a semiarid steppe. Int. J. Remote Sens. 35 (6), 2003-2027.

Xu, M., Zhang, S.Q., Wang, J., Zhao, Q.D., Zhao, C.C., 2014. Temporal and spatial patterns of water storage change of Qilian Mountains in recent 8 years based on GRACE. Arid Land Geogr. 37 (3), 458-467 (in Chinese with English abstract).

Xu, T., Bateni, M.S., Liang, S.L., 2015. Estimating turbulent heat fluxes with a weakconstraint data assimilation scheme: a case study (HiWATER-MUSOEXE). IEEE Geosci. Remote Sens. Lett. 12 (1), 68-72.

Xu, Z.W., Liu, S.M., Li, X., Shi, S.J., Wang, J.M., Zhu, Z.L., Xu, T.R., Wang, W.Z., Ma, M.G., 2013. Intercomparison of surface energy flux measurement systems used during the HiWATER-MUSOEXE. J. Geophys. Res. 118, 13140-13157.

Yang, Y.T., Guan, H.D., Shang, S.H., Long, D., Simmons, C.T., 2014. Towards the use of the MODIS ET product to estimate terrestrial GPP for non-forest ecosystems. IEEE Geosci. Remote Sens. Lett. 11 (9), 1624-1628.

Yang, Y.T., Long, D., Guan, H.D., Liang, W., Simmons, C.T., Batelaan, O., 2015 Comparison of three dual-source remote sensing evapotranspiration models during the MUSOEXE-12 campaign: revisit of model physics. Water Resour. Res. 51 (5), 3145-3165.

Yang, Y.T., Long, D., Shang, S.H., 2013a. Remote estimation of terrestrial evapotranspiration without using meteorological data. Geophys. Res. Lett. 40, 3026-3030.

Yang, Y.T., Shang, S.H., 2013. A hybrid dual source scheme and trapezoid framework based evapotranspiration model (HTEM) using satellite images: algorithm and model test. J. Geophys. Res.: Atmos. 118, 2284-2300.

Yang, Y.T., Shang, S.H., Guan, H.D., Jiang, L., 2013b. A novel algorithm to assess gross primary production for terrestrial ecosystems from MODIS imagery. J. Geophys Res.: Biogeosci. 118, 590-605.

Yang, Y.T., Shang, S.H., Jiang, L., 2012. Remote sensing temporal and spatial patterns of evapotranspiration and the responses to water management in a large irrigation district of North China. Agric. For. Meteorol. 164, 112-122.

Yao, Y., Liang, S., Qin, Q., Wang, K., Zhao, S., 2011. Monitoring global land surface drought based on a hybrid evapotranspiration model. Int. J. Appl. Earth Obs. Geoinf. 13, 447-457.

Zhang, K., Kimball, J.S., Mu, Q., Jones, L.A., Goetz, S.J., Running, S.W., 2009. Satellite based analysis of northern ET trends and associated changes in the regional water balance from 1983 to 2005. J. Hydrol. 379, 92-110.

Zhang, K., Kimball, J.S., Nemani, R.R., Running, S.W., 2010. A continuous satellitederived global record of land surface evapotranspiration from 1983-2006. Water Resour. Res. 46, W09522.

Zhong, M., Duan, J.B., Xu, H.Z., Peng, P., Yan, H.M., Zhou, Y.Z., 2008. Trend of China land water storage redistribution at medi- and large-spatial scales in recent five years by satellite gravity observations. Chin. Sci. Bull. 54 (5), 816-821.

Zhu, G.F., Li, X., Su, Y.H., Zhang, K., Bai, Y., Ma, J.Z., Li, C.B., Hu, X.L., He, J.H., 2014. Simultaneous parameterization of the two-source evapotranspiration model by Bayesian approach: application to spring maize in an arid region of northwest China. Geosci. Model Dev. 7, 741-775. 